\title{
The NMFS Southeast Region Headboat Survey: History, Methodology, and Data Integrity
}

\author{
E. E. FITZPATRICK, E. H. WILLIAMS, K. W. SHERTZER, K. I. SIEGFRIED, J. K. CRAIG, \\ R.T. CHESHIRE, G. T. KELLISON, K. E. FITZPATRICK and K. BRENNAN
}

\section{Introduction}

The NMFS Southeast Region Headboat Survey (SRHS) is administered by the Beaufort Laboratory of the National Marine Fisheries Service's (NMFS) Southeast Fisheries Science Center (SEFSC). The SRHS samples recreational headboats, which typically carry more than 6 passengers. The survey has operated along the southeast U.S. Atlantic coast (SEUS) since 1972. It is the longest continuous time series of recreational fisheries data from federal waters in the SEUS.

The SRHS is composed of industry-reported trip data (referred to as "logbooks," "catch records," or "trip reports") from headboat trips and biological data collected dockside by SRHS port samplers from a subset of trips and anglers. Headboats (also re-

The authors are with the Beaufort Laboratory, Southeast Fisheries Science Center, National Marine Fisheries Service, NOAA, 101 Pivers Island Rd., Beaufort, N.C. 28516-9722.

Corresponding author is Eric Fitzpatrick (Eric. Fitzpatrick@noaa.gov).

doi: https://doi.org/10.7755/MFR.79.1.1 ferred to as "party boats") are distinct from charterboats, which almost always carry six passengers or fewer and charge one fee for the entire boat.

Anglers on headboats pay a perhead fee to target reef fish and coastal migratory pelagic species on full day $(\sim 8 \mathrm{~h})$ or partial day $(\sim 4 \mathrm{~h})$ trips. Some vessels can carry a maximum of nearly 100 passengers and may attain speeds of $25 \mathrm{kn}$ although the average is typically $15 \mathrm{kn}$ (Huntsman, 1976; Fig. 1).

The biological data collected are often used in stock assessments and in life-history studies. The SRHS samples many of the reef-associated and pelagic species managed by the South Atlantic Fishery Management Council (SAFMC). Scientists commonly use the data to estimate landings and to derive indices of abundance. For many stocks in the SEUS, this index is the only source of reliable abundance information prior to 1992 , covering a critical time period in the exploitation history of those species. Our primary goal here was to explore the reliability of SRHS data collected from federal waters in the SEUS. We did this

ABSTRACT-The Southeast Region Headboat Survey (SRHS) is administered by the Beaufort Laboratory of the NMFS Southeast Fisheries Science Center. The SRHS samples recreational headboats, wherein fishermen pay by the "head" and boats typically carry more than 6 passengers. The survey has operated along the southeast U.S. Atlantic since 1972 and in the Gulf of Mexico since 1986. It is the longest continuous time series of recreational fisheries data from federal waters along the southeast coast. The SRHS data consist of trip-level logbook records submitted by captains and biological samples collected dockside by professional port agents. Our study, focused on the SRHS in southeast U.S. Atlantic, was initiated a) to document the history, protocols, and methodological changes to the SRHS, and b) to estimate the prevalence of misreporting in the survey. We recommend that our results be used to guide the filtering of logbook records containing apparently erroneous information. However, more generally, our results indicate that the SRHS data are robust. We expect the survey will continue to support stock assessments, management advice, and other studies of economically important fish species. through two main lines of investigation: a) document the history, protocols, and methodological changes to the SRHS, and b) estimate the prevalence of apparent or likely misreporting in the survey.

\section{History, Methodology, and Protocols}

\section{History of the Headboat Fleet and Survey}

Prior to 1970, exploration of the continental shelf off of North Carolina and South Carolina was mainly limited to commercial fishing methods targeting demersal fish concentrations and usually avoided areas not amenable to trawl gear (Huntsman, 1976). The headboat fishery developed in the SEUS in the 1920's and 1930's at a relatively small scale but became more prevalent in the SEUS in the mid-1960's.

During this early period, headboat captains often fished commercially when tourist activity was low and operated headboat trips when profitable. Most vessels were wooden and fished close to shore (i.e., within sight of land). Following World War II (1945), U.S. military boats became available to the public as surplus, and many were purchased for use as headboats (Huntsman, 1976). These vessels were technologically advanced for this time period, with significant horsepower and steel hulls that were capable of carrying many passengers.

Fishing off South Carolina's Little River was detrimentally impacted in 1954 following a direct landfall of Hurricane Hazel (Burrell, 2000), and only two headboats remained in the fishery. In the winter of 1958 off the North Carolina coast, unusually cold 


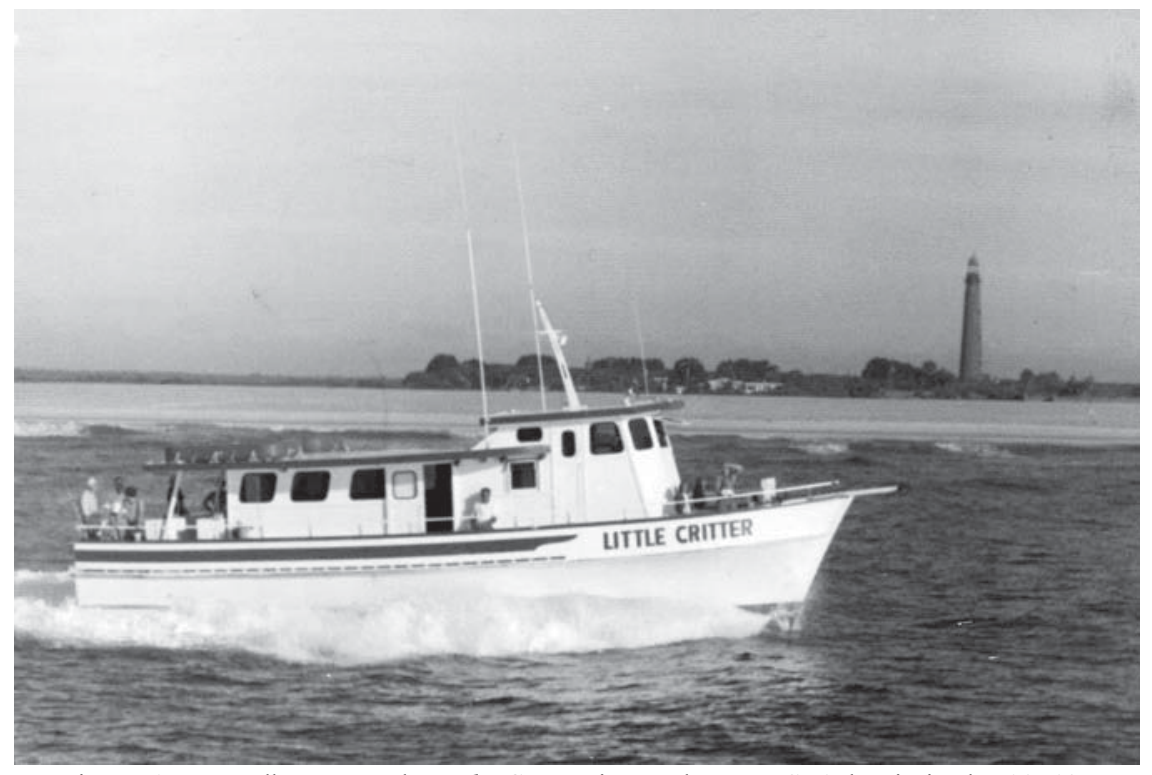

Figure 1.-Headboat vessel, Little Critter, in southeast U.S. Atlantic in the 1970's.

water intruded onto the continental shelf, resulting in widespread mortality of demersal fishes (McLain et al. ${ }^{1 ;}$ Simpson ${ }^{2}$ ). The magnitude of this event was not fully quantified but commercial landings of snapper-grouper species declined from nearly 135 metric tons (t) in 1957 to nearly zero the following year (Power, 1959).

From the 1940's through the 1960's the headboat fishery steadily expanded geographically as did the number of vessels participating. Headboat operations were located near barrier island inlets in coastal towns such as Morehead City and Carolina Beach, North Carolina; Little River, Murrells Inlet, and Charleston, South Carolina; Mayport, St. Augustine, Ponce Inlet, Jupiter, Miami, and Key West, Florida (Fig. 2).

Ellis et al. (1958) estimated that in 1955 there were 164 headboats operating in Florida waters, 83 on the

\footnotetext{
${ }^{1}$ McLain, D. R, F. V. Mayo, and M. J. Owen. Monthly maps of sea surface temperature anomalies in the northwest Atlantic Ocean and Gulf of Mexico, 1948-1967. Unpubl. manuscr. Pac. Environ. Group, Natl. Mar. Fish. Serv., NOAA, c/o Fleet Numerical Weather Central, Naval Post Graduate School, Monterey, CA 93940, 13 p.

${ }^{2}$ Simpson, B. 1974. Headboats divulge catch figures to NMFS, aid Carolina fishery. Natl. Fisherman Mag. 54(7), 10 p.
}

east (Atlantic) coast and 81 on the west (Gulf) coast. Huntsman (1976) reported that about 25 headboats operated from Cape Hatteras, N.C., to Charleston, S.C., from 1972 to 1973. Estimates of the annual number of headboats operating in the SEUS have fluctuated since the early 1970's, ranging from 32 to 99 . From the 1980's to was relatively constant in the SEUS, with about 70-80 vessels. A decline in the number of headboats began in the early 2000 's, likely due to multiple factors, including declining fish stocks, more restrictive regulations, and other economic factors (e.g., high operational costs and increases in the number of private fishing vessels).

Tackle used during headboat trips is sturdy enough to resist abrasion from heavy fish and hard bottom structure, as well as the stresses of frequent use often by inexperienced anglers (Huntsman, 1976). Solid, 5- to 6-ft, fiberglass rods are standard. Typically, reels are size $6 / 0$ to $9 / 0$ and line is $80-120-1 b$ test monofilament. During the 1970's in North Carolina and South Carolina, electric reels were used on a small number of headboats to improve efficiency while increasing catch rates, primarily in deeper waters. The bottom the 1990's the number of headboats rigs consist of small to medium size "J" and circle hooks, usually two per rig.

A typical full-day trip begins at daybreak and lasts approximately 8-10 h. Headboats fish in depths from $\sim 25$ to $\sim 145$ m (Huntsman, 1976). After transit to the fishing ground, anglers spend about 6-8 h fishing before returning to port. Captains tend to avoid fishing at greater depths due to increased tangling, and because stronger currents in those depths often prevent the lines from reaching the bottom. Depending on conditions, captains may anchor before angling begins, or may allow clients to fish while the vessel drifts.

Headboats often target species contained in the SAFMC Snapper Grouper complex. ${ }^{3}$ Distributions of snapper-grouper species are dependent on many factors, with latitude and depth among the most important (Shertzer and Williams, 2008). A complex, inner-shelf $(<30 \quad \mathrm{~m})$ community, dominated numerically by species such as black sea bass, Centropristis striata; grunts (Haemulidae), and porgies (Sparidae), is present from North Carolina to Cape Canaveral, Fla. The mid-shelf region $(30-100 \mathrm{~m})$ is populated by a diverse group of species, whose distributions often extend into shallower or deeper waters, including but not limited to red porgy, Pagrus pagrus; vermilion snapper, Rhomboplites aurorubens; red snapper, Lutjanus campechanus; gray triggerfish, Balistes capriscus; red hind, Epinephelus guttatus; scamp, Mycteroperca phenax; speckled hind, Epinephelus drummondhayi; and knobbed porgy, Calamus nodosus (Grimes, 1978; Chester et al., 1984). A distinctive community of deepwater $(>100 \mathrm{~m})$ groupers (Epinephelus, Hyporthodus, and Mycteroperca) occurs at and beyond the continental shelf edge. A gradual shift in the species assemblage occurs south of Cape Canaveral where gray snapper, Lutjanus griseus; lane snapper, L. synagris; mutton snapper, L. analis; and

${ }^{3}$ See $h t t p: / / s a f m c . n e t / r e s o u r c e-l i b r a r y /$ snappergrouper. 


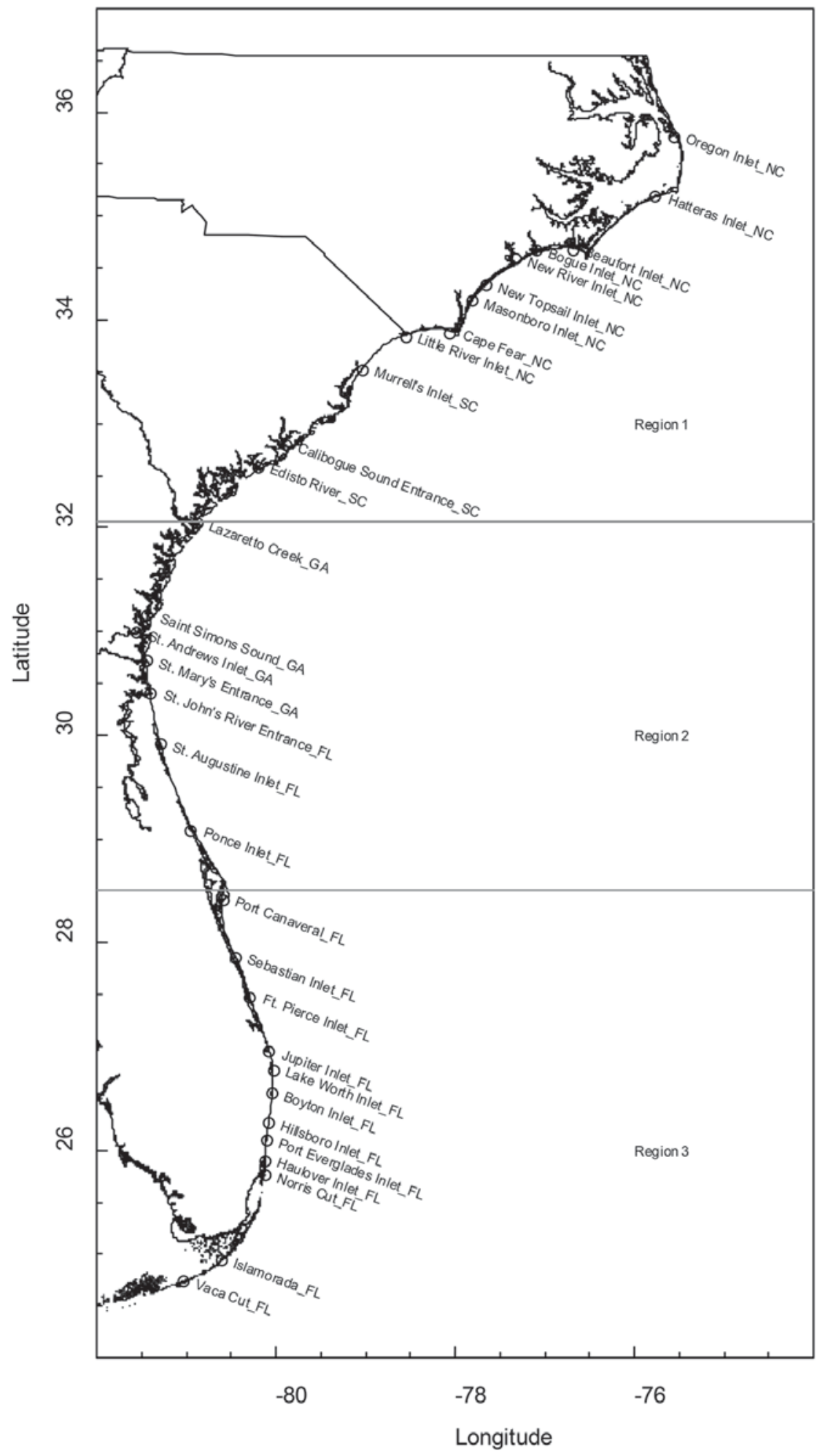

Figure 2.-Common fishing inlets used in the headboat fishery in the Carolinas, Georgia-northeast Florida, and southeast Florida regions. The three regions were used for species-specific catch record analyses. yellowtail snapper, Ocyurus chrysurus, are more prevalent (Shertzer et. al., 2009).

In the early 1970's, SEFSC staff recognized that the recreational headboat fishery accounted for substantial landings for many of the species listed above (e.g., $725 \mathrm{t}$ of marketable fish landed in 1973 from the Carolinas (Huntsman, 1976)). As a result, the SRHS was initiated in 1972 in North Carolina and South Carolina by NMFS staff at the SEFSC Beaufort Laboratory, with the objective of monitoring the headboat fishery and collecting biological samples dockside to determine average weights by species and to estimate total removals by weight. In 1976 the survey expanded to Georgia and northeast Florida (Nassau-Indian River counties), and then to southeast Florida (St. LucieMonroe counties) in 1978. In the early decades (1972-91) of the SRHS, these data were the primary source of fishery-dependent information on age and growth, and on relative abundances of fishes in the snapper-grouper complex.

\section{Methodology}

The SRHS survey design incorporates logbook reporting from headboat vessels and dockside sampling by NMFS port agents. The SRHS is divided into discrete geographic/statistical areas to which headboat trips are assigned and landings estimated. The three main components of the SRHS data collection are the dockside intercept sampling program (DISP), the headboat activity report (HAR), and the logbook, commonly called the trip report or catch record (CR).

The DISP obtains length and weight data from landings to determine the size distribution and mean size of species landed by the headboat fishery. Port agents also collect otoliths, spines, and occasionally gonads to characterize age distributions, sex ratios, and reproductive traits. Port agents may collect other biological samples (e.g., stomachs, fin clips) in support of specific research projects or management needs (e.g., trophic interactions, stock structure). 
The survey design for the DISP can best be described as a systematic opportunistic design. Each port agent assigned to a particular area is required to sample all headboats within their area of responsibility in a systematic rotation, ideally sampling each vessel at least once each month during periods of operation. In some areas, headboat trips occur year-round (e.g., southeast Florida), while in other areas there are periods (typically winter) during which no trips occur (e.g., North Carolina and South Carolina). The operational schedules of individual vessels show considerable variation, and it is rare that agents are able to sample vessels in an exact and repeatable rotation. Consequently, SRHS port agents can adjust their sampling schedules to ensure sampling of all vessels approximately the same number of times each month during periods of operation.

When conducting dockside intercept sampling, port agents are instructed to identify themselves as NMFS port agents conducting a survey of headboat fishing. They are further instructed to identify and select anglers with unusual, uncommon, or rare species in their catches (on stringers, in coolers, etc.). The rationale for this approach is that if catches with uncommon fish are selected, sufficient numbers of more common species will likely be obtained as well. Port agents are instructed to measure and weigh all fish from selected catches. However, once they have measured 10 fish of a given species, they are not required to (but may if time allows) measure additional individuals of that species from additional catches sampled from that trip. This approach allows port agents to spend more time collecting information on less common species while collecting sufficient information on more common species.

Upon obtaining an angler's catch for sampling, the port agent measures and weighs individual fish, typically using an electronic fish measuring board connected to an electronic balance, but at times (historically and currently if there are equipment malfunctions) us- ing non-electronic measuring boards and scales. All measurements are recorded into computer memory for later download. While sampling, the port agent often performs education and outreach functions by answering bystanders' questions about the SRHS, fish biology, fish identification, fish ecology, fisheries regulations, and fisheries management.

The second main component of the SRHS is the headboat activity report (HAR). Port agents record all known information about a vessel's activity (e.g., trip date, trip type, and number of anglers) on the HAR, regardless of whether a trip was sampled under the DISP. These observations are used to track compliance (a vessel is compliant if all trips are reported) and to correct for misreporting or non-reporting. The HAR observations are collected by multiple methods including direct observation, contact with the vessel's ticket office to confirm activity, incorporation of observations made by samplers from other surveys (e.g., MRIP samplers) and, in recent years, by checking websites for fishing trips.

The third main component of the SRHS is the logbook report (CR). The CR was originally designed to be a census, but fluctuations in reporting cooperation have resulted in changes in methodology over time. The survey has always asked or required (see below) vessel personnel to complete selfreported logbooks of catch and effort for each trip. From 1972 to 2012 the mechanism used by captains and crew to report catch and effort was a onepage, paper logbook form. The paper form originally used in North Carolina and South Carolina listed several of the most commonly caught species in the Carolinas. As the survey expanded in the SEUS, the logbook form was altered to reflect the species typically caught in specific geographic areas. Unique forms were created for North Carolina, northeast Florida, and southeast Florida. Due to the limited amount of space (one page), the form for each geographic area contained only those species that were most likely to be kept in that region.
The number of species on a single form has expanded from a low of 24 for the Carolinas in 1972 to a high of 74 for Georgia-northeast Florida in 1986. The area-specific logbook forms also changed several times to accommodate additional data elements (Appendix 1). The most recent change, made in 2004, included the addition of fields for the number of paying customers who actively fished on a particular trip, the number of fish released alive, and the number of fish released dead.

Table 1 summarizes the major changes to the logbook report forms and includes the addition of species and trip information. Sixteen different forms were used between 1972 and 2013, with subtle changes occurring more frequently in the late 1970's and major changes occurring in 1980, 1984, 1992, and 2004 that correspond to increased data needs, major regulatory changes, and increases in computer memory and processing capabilities.

In 2009, the SRHS conducted a pilot project to test the feasibility of developing an electronic logbook reporting system. Software was installed on eight vessels in the SEUS: two in North Carolina, two in South Carolina, one in Georgia, and three in Florida. The project concluded in November 2010. The results from this project and feedback from captains were favorable regarding the application and ease of use of the electronic logbooks (Appendix 2). Project results indicated that electronic reporting would streamline data collection and facilitate the timely completion of data analysis to support stock assessments and fishery management.

The SRHS electronic logbook (eLog) was implemented in 2013. Since implementation, the SRHS eLog has been updated several times, with most updates restricted to minor adjustments that did not affect the user. The most significant update that did impact the user was in August 2014, when four socioeconomic fields were added: number of paying passengers, number of crew, amount of fuel used, and price per gallon of fuel. 
Table 1.-Summary of the changes documented in southeast Regional Headboat Survey (SRHS) forms used in the southeast U.S. Atlantic headboat fishery, $1973-2004$.

\begin{tabular}{|c|c|c|c|c|c|}
\hline Year & Form \# & No. of species & $\begin{array}{l}\text { Black sea bass } \\
\text { (units) }\end{array}$ & Discards & $\begin{array}{l}\text { Additions to header/master information } \\
\text { and other major changes }\end{array}$ \\
\hline 1972 & 1 & 24 & No. of $100 \mathrm{lb}$. boxes & & Number captured, vessel, date, number of anglers aboard \\
\hline 1976 & $2,3,4,5$ & $\begin{array}{l}(\mathrm{NC} / \mathrm{SC}): 35 \\
(\mathrm{GA} / \mathrm{FL}): 32\end{array}$ & No. of $100 \mathrm{lb}$. boxes & & (Florida added), location, full, $1 / 2$, and $3 / 4$ day \\
\hline 1978 & $4,5,6,7$ & $\begin{array}{l}\text { (NC/SC): } 35 \\
(\mathrm{GA} / \mathrm{FL}): 31\end{array}$ & Pounds & & a.m., p.m. \\
\hline 1980 & 8,9 & $\begin{array}{l}\text { (NC/SC): } 36 \\
(\mathrm{GA} / \mathrm{FL}): 67\end{array}$ & Pounds & Hand written by species, inconsistent & $\begin{array}{l}\text { Night, overnight, captain signature, blank lines to add in species and } \\
\text { number discarded }\end{array}$ \\
\hline 1984 & 10,11 & $\begin{array}{l}\text { (NC/SC): } 62 \\
(\mathrm{GA} / \mathrm{FL}): 71\end{array}$ & Pounds & Hand written by species, inconsistent & $\begin{array}{l}\text { Number Captured changed to Number Caught, Night (1st, 2nd), } \\
\text { Departure Time, agency use only section }\end{array}$ \\
\hline 1986 & 12,13 & $\begin{array}{l}\text { (NC/SC): } 64 \\
(\mathrm{GA} / \mathrm{FL}): 74\end{array}$ & Pounds & Hand written by species, inconsistent & $\begin{array}{l}\text { King Mackerel, Spanish Mackerel, Cero, Dolphin, Cobia, Little Tunny } \\
\text { above bold black line with mandatory reporting statement "It is unlawful } \\
\text { to falsify or fail to report...". Added in July, deleted in October. }\end{array}$ \\
\hline 1992 & 14,15 & 69 & $\begin{array}{l}\text { No. and wt. ( } \mathrm{SC} \text { released } \\
\text { on few forms) }\end{array}$ & $\begin{array}{l}\text { South Carolina only - very few vessels, } \\
\text { released ('92-'03), released alive } \\
\text { and dead ('00-'02) }\end{array}$ & \\
\hline 2004 & 16 & 69 & $\begin{array}{l}\text { No., wt., released alive, } \\
\text { released dead }\end{array}$ & $\begin{array}{l}\text { Released alive and dead standard } \\
\text { on all forms and areas }\end{array}$ & Distance from shore, pay type, number of anglers who fished \\
\hline
\end{tabular}

Currently the SRHS eLog requires the following fields to be completed for each trip: date(s) and duration of the fishing trip; vessel and captain's names; number of anglers and number of paying passengers; number of crew, number of gallons of fuel used, and price per gallon of fuel; geographic location of fishing activity in latitude and longitude degrees and minutes (optional point and click maps); minimum and maximum of primary depths fished; number of individuals of each caught species that were kept; and number of individuals of each caught species that were released either alive or dead.

From 1972 to 1995, logbook reporting was voluntary for headboats participating in the SRHS. Starting in 1972, as part of the strategy to encourage captains to report, participating vessels in the SEUS were paid for reporting. The amount of payment was related to the length of a trip, which in turn affected the size and complexity of the catch. Vessel personnel were paid $\$ 1.50$ for each record of a "full" day trip, $\$ 1.25$ for a "three-quarter" day trip, and $\$ 1.00$ for a "half" day trip.

Payment for participation in the SEUS survey continued until logbook reporting became mandatory in 1995 with Amendment 7 to the SnapperGrouper Fishery Management Plan (Code of Federal Regulations 646.4). This amendment required charter vessels and headboats to be in possession of a permit in order to fish for snapper and grouper. As a condition of this permit, the reporting requirements (FR 622.5) state "charter vessel/headboat owners and operators that if selected to report by the SEFSC, must maintain a fishing record for each trip." The rule further states that headboats are required to report on a monthly basis by submitting logbooks within seven days of the end of each month. From 1995 to 2013 , reporting requirements were unchanged.

In January 2014, NOAA published a final rule for the For-Hire Reporting Amendment (Amendment 31 to the Fisheries Management Plan for the Snapper-Grouper Fishery of the South Atlantic Region, Amendment 6 for the Dolphin and Wahoo Fishery of the Atlantic, and Amendment 22 for the Coastal Migratory Pelagic Resources in the Atlantic and the Gulf of Mexico) which modified headboat reporting requirements for the SEUS. The notable changes addressed when and how to report. First, the rule required headboat personnel to submit fishing records to the SEFSC on a weekly basis. Second, the rule changed the method of submission from mailing paper forms to submitting forms electronically. Third, the rule prohibited headboat owners and operators who are delinquent in submitting reports from continuing to harvest or possess snapper-grouper and coastal migratory pelagic species until they have submitted the required reports.

\section{Protocols}

Since the inception of the SRHS, the broad objective to characterize the headboat fleet has remained the same while subtle changes in data collection practices have occurred to address an increase in management needs, or to actively improve the survey using current technologies (e.g., the change from paper to electronic reporting; the change from monthly to weekly reporting to support monitoring needs needs). Although the data management practices in the early years of the program were not well documented, the goals were always clear: summarize effort and landings while accounting for missing or incomplete records. All landings and effort estimates, including correction factors (adjustment for missing catch records), were calculated manually in the early years.

In recent years, reported effort has been summed by month and vessel after converting number of anglers to angler days. An "angler day" is the amount of effort expended by one angler, using rod and reel, on a full day fishing trip (usually $8 \mathrm{~h}$ ), and includes travel time to and from the fishing grounds (e.g., 40 anglers on a half-day trip would yield 20 angler days). To adjust for incomplete reporting, information summarized on a HAR is used to estimate total effort. Total estimated effort (estimated angler days) is then divided by reported effort (reported angler days) to calcu- 
late a correction factor used to adjust reported landings.

Landings estimates are provided by species, area, and month. Effort correction factors are calculated by month and vessel to adjust for misreporting. These correction factors are applied to the reported landings by species-vessel-month combinations to generate total estimated numbers of fish landed. These numbers are then multiplied by mean weights of fish calculated from the biological profile (BP) data by species-area-month combinations to generate a total weight of fish landed for each species-vessel-month combination. These fine-scale estimates are then summed at courser scales to provide landings estimates for stock assessments and quota monitoring.

Historically, logbooks submitted substantially late were counted as missed trips so that estimates of landings and discards were not subjected to substantial recall bias. For such cases, landings and discard data were subsequently estimated using conversion factors. However, the specific policy defining "substantially late" was not documented, and decisions may have been made on a case-by-case basis based on guidance from the local port agent. Once the logbooks were received at the Beaufort Laboratory, survey personnel checked them again to ensure there were no obvious errors. Data entry contractors used key entry verification procedures (data were entered twice, and the two datasets compared to one another) to ensure that data were entered correctly.

Current quality assurance procedures within the database (SRH Oracle system $^{4}$ ) focus mainly on the BP data. Port agents load BP data directly from the electronic fish measuring board (FMB) text files into the SRH Oracle system. When not using FMB's, port agents will record measurements on a paper form and enter the data directly into the SRH Oracle system through a data entry form. The FMB text files contain various delimiters. The Oracle

\footnotetext{
${ }^{4}$ Mention of trade names or commercial firms does not imply endorsement by the National Marine Fisheries Service, NOAA.
}

upload system checks that these delimiters are in place and are valid; if any delimiters are entered incorrectly the upload is rejected. The Oracle system also rejects any upload where the species codes do not match. Once the data are loaded, the port agents are instructed to review each collection for accuracy and completeness.

\section{Analysis of Data Integrity}

\section{Methods}

The self-reported SRHS data lack any independent validation source, relegating any analysis of potential misreporting to methods of outlier detection. The misreporting analysis focused on data spanning 41 years (1972-2013) and involved two main components: 1) analysis of industryreported catch records (CR's) to identify outliers, which might be indicative of misreporting, and 2) comparison of trip-level catch records with data collected by SRHS port agents (BP's) during DISP surveys. Both components are described below.

\section{Outlier Analysis}

The self-reported CR's were analyzed using two lines of investigation. The first approach focused on the landings of individual species reported, and the second approach examined the species composition of reported trips from vessels operating in southeast U.S. Atlantic water. For both of these approaches, comparisons were made among vessels from similar geographic locations that would be expected to fish in similar areas and, therefore, show similar trends in landings. In addition, comparisons were made within distinct time periods, to account for changes in fleet dynamics over time. Fifteen area-time blocks (Table 2) were developed using inlet information (Fig. 2) and multivariate statistical techniques similar to those of Shertzer et al. (2009) were applied, resulting in three distinct spatial areas. Regulatory changes in the fishery were reviewed to determine time periods. These area-time blocks were used to define common patterns in catches, and to identify individual vessels that deviated from the common patterns (i.e., outlier vessels). Outlier vessels were investigated to determine whether deviations in catch could be explained by unique characteristics of particular vessels or whether misreporting was a more likely explanation.

Species that were present in at least $15 \%$ of headboat trips in at least one of these 15 area-time blocks were included in the analysis. Various methods were examined to identify species to include in the analysis (i.e., all species, present in 1-10\% of trips) but $15 \%$ was chosen as the "cutoff" to maximize the number of species that were encountered in all 15 area-time blocks. In some cases, a species was rare in one area and common in another because of changes in species assemblage structure with latitude (Shertzer et al., 2009).

Analyses of the CR's were conducted to identify individual vessels within each area-time block combination $(n=15)$ that were outlier vessels and, therefore, potentially misreporting. A single vessel could be identified as an outlier vessel in multiple area-time blocks. These analyses relied on 62 metrics designed to flag different types of potential misreporting associated with various species (Table 3). Fifty of these metrics (two metric types X 25 species) (metric numbers 5 and 10 in Table 3) focused on the reported landings of 25 individual species, and twelve focused on metrics describing species compositions (metric numbers $1-4,6-9,11$, and 12 in Table 3 ). With 637 vessel-area-time block combinations and 62 metrics, there were 39,494 metrics that could potentially be flagged. For detecting outliers, we used a modified z-score computed as,

$$
z=\left(0.65\left(x_{i}-x\right) / \mathrm{MAD}\right),
$$

where MAD denotes the median absolute deviation, $x_{i}$ is the value of a particular metric for vessel $i$, and $x$ is the median of that particular metric for all vessels in a particular area-time block (Iglewicz and Hoaglin, 1993; Hammer et. al., 2010). A modified $z$-score was defined as an outlier if $|z|>3.5$ 
Table 2.-Bold values represent species kept in at least $15 \%$ of headboat trips indicating common species in the Atlantic used in the species-specific catch record (CR). Value represents the proportion of trips with at least one species recorded within area-time blocks. Excluding Black Sea Bass and Bank Sea Bass, the species in this table were used for the species-specific catch record (CR) analyses.

\begin{tabular}{|c|c|c|c|c|c|c|c|c|c|c|c|c|c|c|c|c|}
\hline \multirow[b]{2}{*}{ Common Name } & \multirow[b]{2}{*}{ Scientific Name } & \multicolumn{5}{|c|}{ Carolinas } & \multicolumn{5}{|c|}{ Georgia \& North Florida } & \multicolumn{5}{|c|}{ South Florida } \\
\hline & & $\begin{array}{c}1972- \\
1983\end{array}$ & $\begin{array}{c}1984- \\
1991\end{array}$ & $\begin{array}{c}1992- \\
2000\end{array}$ & $\begin{array}{c}2001- \\
2009\end{array}$ & $\begin{array}{c}2010- \\
2013\end{array}$ & $\begin{array}{c}1972- \\
1983\end{array}$ & $\begin{array}{c}1984- \\
1991\end{array}$ & $\begin{array}{c}1992- \\
2000\end{array}$ & $\begin{array}{c}2001 \\
-2009\end{array}$ & $\begin{array}{c}2010- \\
2013\end{array}$ & $\begin{array}{c}1972- \\
1983\end{array}$ & $\begin{array}{c}1984- \\
1991\end{array}$ & $\begin{array}{c}1992- \\
2000\end{array}$ & $\begin{array}{c}2001- \\
2009\end{array}$ & $\begin{array}{c}2010- \\
2013\end{array}$ \\
\hline Black Sea Bass & Centropristis striata & 79.3 & 86.6 & 75.7 & 70.6 & 59.7 & 78.4 & 82.3 & 59.4 & 66.6 & 66.0 & 4.8 & 9.3 & 11.3 & 20.9 & 11.4 \\
\hline Vermilion Snapper & Rhomboplites aurorubens & 31.4 & 29.9 & 41.6 & 32.7 & 20.8 & 82.5 & 90.6 & 54.1 & 83.0 & 58.8 & 20.7 & 23.7 & 11.5 & 12.3 & 10.7 \\
\hline Gray Triggerfish & Balistes capriscus & 30.6 & 22.4 & 43.0 & 34.5 & 29.5 & 51.2 & 52.6 & 50.9 & 59.7 & 71.3 & 19.6 & 26.4 & 21.9 & 26.3 & 31.4 \\
\hline Tomtate & Haemulon aurolineatum & 33.6 & 46.3 & 45.9 & 24.6 & 28.4 & 57.2 & 86.7 & 44.1 & 17.0 & 25.2 & 8.7 & 16.6 & 9.0 & 8.0 & 8.7 \\
\hline Gag & Mycteroperca microlepis & 24.0 & 25.5 & 23.9 & 19.6 & 14.8 & 49.6 & 43.1 & 50.7 & 33.1 & 18.3 & 10.6 & 9.4 & 12.1 & 12.5 & 2.6 \\
\hline King Mackerel & Scomberomorus cavalla & 1.2 & 12.7 & 21.8 & 19.0 & 8.6 & 21.0 & 18.9 & 16.6 & 17.0 & 5.6 & 51.3 & 45.8 & 34.9 & 31.5 & 28.2 \\
\hline Gray Snapper & Lutjanus griseus & 0.1 & 0.3 & 1.2 & 2.6 & 0.4 & 21.4 & 29.2 & 45.4 & 42.8 & 29.2 & 17.9 & 25.2 & 39.3 & 41.4 & 35.3 \\
\hline Red Snapper & Lutjanus campechanus & 16.0 & 15.4 & 12.8 & 10.8 & 0.4 & 69.9 & 52.4 & 46.5 & 72.3 & 2.2 & 5.1 & 5.6 & 5.5 & 13.1 & 0.4 \\
\hline White Grunt & Haemulon plumierii & 26.1 & 26.8 & 44.1 & 38.5 & 34.6 & 0.6 & 2.5 & 7.6 & 4.2 & 5.3 & 10.9 & 18.5 & 28.9 & 36.4 & 31.4 \\
\hline Whitebone Porgy & Calamus leucosteus & 10.3 & 18.4 & 31.1 & 14.0 & 6.3 & 21.2 & 51.8 & 43.1 & 33.4 & 45.9 & 1.6 & 3.5 & 4.0 & 5.9 & 9.2 \\
\hline Yellowtail Snapper & Ocyurus chrysurus & 0.1 & 0.3 & 0.6 & 0.8 & 0.2 & 5.1 & 11.4 & 2.2 & 10.9 & 2.1 & 50.8 & 48.1 & 54.2 & 52.1 & 54.2 \\
\hline Red Porgy & Pagrus pagrus & 44.0 & 34.2 & 31.0 & 25.6 & 16.3 & 42.6 & 24.4 & 9.8 & 11.1 & 5.7 & 6.4 & 6.6 & 1.3 & 0.7 & 1.7 \\
\hline Atlantic Sharpnose Shark & Rhizoprionodon terraenovae & 0.0 & 0.3 & 14.3 & 22.3 & 36.1 & 0.0 & 4.5 & 44.6 & 53.1 & 48.0 & 0.0 & 0.1 & 3.5 & 11.8 & 7.4 \\
\hline Greater Amberjack & Seriola dumerili & 13.0 & 17.7 & 17.3 & 14.6 & 10.9 & 41.2 & 30.0 & 27.5 & 29.2 & 21.8 & 8.4 & 6.2 & 3.1 & 3.5 & 1.6 \\
\hline Lane Snapper & Lutjanus synagris & 0.0 & 0.0 & 0.1 & 0.0 & 0.0 & 11.6 & 15.1 & 35.8 & 40.8 & 19.4 & 10.3 & 22.3 & 29.0 & 28.3 & 19.4 \\
\hline Mutton Snapper & Lutjanus analis & 0.1 & 0.0 & 0.1 & 0.1 & 0.2 & 3.2 & 3.9 & 7.5 & 8.6 & 5.1 & 44.3 & 36.3 & 31.3 & 31.6 & 29.7 \\
\hline Little Tunny & Euthynnus alletteratus & 0.1 & 4.3 & 7.3 & 4.5 & 5.4 & 4.4 & 23.9 & 15.7 & 7.1 & 6.8 & 10.1 & 31.9 & 20.7 & 14.9 & 24.1 \\
\hline Scamp & Mycteroperca phenax & 22.4 & 25.7 & 28.7 & 22.3 & 11.4 & 5.6 & 7.2 & 19.6 & 16.8 & 4.7 & 4.4 & 3.6 & 3.1 & 3.2 & 0.6 \\
\hline Blue Runner & Caranx crysos & 0.4 & 1.3 & 1.6 & 1.4 & 0.6 & 1.0 & 4.3 & 1.4 & 2.1 & 1.4 & 29.1 & 31.2 & 21.9 & 16.6 & 25.7 \\
\hline Spottail Pinfish & Diplodus holbrookii & 12.5 & 17.3 & 19.2 & 23.0 & 28.9 & 0.5 & 10.9 & 13.0 & 6.1 & 5.9 & 0.1 & 0.0 & 0.1 & 0.3 & 0.1 \\
\hline Cobia & Rachycentron canadum & 0.5 & 2.4 & 4.4 & 4.4 & 3.3 & 7.7 & 18.4 & 19.7 & 26.1 & 21.7 & 4.7 & 4.5 & 6.0 & 5.8 & 7.2 \\
\hline Red Grouper & Epinephelus morio & 3.5 & 2.8 & 12.1 & 10.4 & 3.2 & 15.8 & 8.0 & 7.8 & 7.5 & 1.6 & 13.0 & 10.5 & 16.5 & 17.7 & 6.1 \\
\hline Knobbed Porgy & Calamus nodosus & 10.4 & 17.9 & 22.1 & 9.8 & 2.8 & 2.0 & 1.5 & 0.6 & 0.5 & 0.3 & 9.3 & 10.8 & 9.3 & 14.3 & 11.1 \\
\hline Bank Sea Bass & Centropristis ocyurus & 0.0 & 13.5 & 21.5 & 15.0 & 12.6 & 0.0 & 26.3 & 11.1 & 9.1 & 9.4 & 0.0 & 0.1 & 0.2 & 0.2 & 0.2 \\
\hline Great Barracuda & Sphyraena barracuda & 0.2 & 2.9 & 4.1 & 2.8 & 1.3 & 2.8 & 10.6 & 17.5 & 15.8 & 14.2 & 16.3 & 8.9 & 8.6 & 3.5 & 1.6 \\
\hline Sand Perch & Diplectrum formosum & 0.3 & 11.4 & 6.3 & 4.5 & 3.3 & 0.9 & 21.9 & 4.2 & 1.6 & 1.5 & 0.1 & 0.5 & 0.3 & 0.6 & 0.8 \\
\hline Atlantic Bonito & Sarda sarda & 0.0 & 1.1 & 0.3 & 0.2 & 0.3 & 9.3 & 0.0 & 0.0 & 0.0 & 1.5 & 20.4 & 0.0 & 0.0 & 0.0 & 2.0 \\
\hline
\end{tabular}

(Iglewicz and Hoaglin, 1993). Data from vessels with flagged metrics were examined further to identify potential explanations (e.g., presence of inshore species on logbook, indicative of inshore fishing and thus not suggestive of misreporting).

The second approach investigated variations in species composition of the catch among vessels within each area-time block. Non-metric multidimensional scaling (NMDS) was applied in three-dimensional Euclidean space (McCune and Grace, 2002). Euclidean distance measures from the origin were transformed to modified z-scores to identify outlier vessels. A flagged metric (outlier) indicates a significant deviation from the median, whether the median is the median number of fish caught, the median number of anglers, or the species composition in that area-time block.

\section{Trip-level CR-BP Analysis}

The BP data collected dockside were compared with the logbook records (CR's) from those same trips to identify discrepancies indicative of catch misreporting. BP records cannot be matched directly to a CR, so vessels and data were used to match records.

After assessing multiple approaches to identifying individual trips, we determined that the optimal approach was to use vessel number and date to identify individual trips. Because some vessels can make more than one trip in a single day, the matching analysis was constrained to trips on dates for which a vessel was sampled and reported a single trip.

The number of fish measured in the BP data were compared to the number of fish reported on the CR's for

Table 3. - List and description of metrics developed to identify misreporting used by vessel for the species-specific catch record (CR) analyses.

\begin{tabular}{|c|c|c|c|}
\hline $\begin{array}{l}\text { Metric } \\
\text { Number }\end{array}$ & $\mathrm{n}$ & Type of potential misreporting & Description \\
\hline 1 & 1 & Consistently report high or low number of total catch & Relative ranking of the mean of reported catch among vessels by area and time period \\
\hline 2 & 1 & Consistently report high or low catch rates & Relative ranking of the mean of reported CPUE among vessels by area and time period \\
\hline 3 & 1 & Consistently report high or low number of species & Relative ranking of the mean of reported count of all species among vessels by area and time period \\
\hline 4 & 1 & Consistently report very few species or many species & Relative ranking of the mean of the Shannon-Wiener index value among vessels by area and time period \\
\hline 5 & 25 & Consistently report low or high numbers of species ' $\mathrm{x}$ ' & Relative ranking of the mean catch for each of 25 species among vessels by area and time period \\
\hline 6 & 1 & Consistently report the same number of individuals & Relative ranking of the variance of reported catch among vessels by area and time period \\
\hline 7 & 1 & Consistently report the same catch rates & Relative ranking of the variance of reported CPUE among vessels by area and time period \\
\hline 8 & 1 & Consistently report the same number of species & $\begin{array}{l}\text { Relative ranking of the coefficient of variation of reported count of all species among vessels by } \\
\text { area and time period }\end{array}$ \\
\hline 9 & 1 & $\begin{array}{l}\text { Consistently report the same level of species diversity } \\
\text { at the trip level (similar to spcount.cv) }\end{array}$ & $\begin{array}{l}\text { Relative ranking of the coefficient of variation of the Shannon-Wiener index value among vessels } \\
\text { by area and time period }\end{array}$ \\
\hline 10 & 25 & Consistently report similar catch rates for species ' $\mathrm{x}$ ' & $\begin{array}{l}\text { Relative ranking of the variation in CPUE for each of the } 25 \text { species among vessels by area } \\
\text { and time period }\end{array}$ \\
\hline 11 & 2 & $\begin{array}{l}\text { Report species that are much different than similar } \\
\text { vessels fishing in similar habitat }\end{array}$ & Non-metric multi-dimensional scaling (NMDS) - presence/absence of 25 species \\
\hline 12 & 2 & $\begin{array}{l}\text { Report species catch rates that are much different } \\
\text { than similar vessels fishing in similar habitat }\end{array}$ & Non-metric multi-dimensional scaling (NMDS) - CPUE of 25 species \\
\hline
\end{tabular}


Table 4.-Number of reported trips, estimated trips, and reporting compliance rate (defined as reported trips no more than 8 days after the fishing week/estimated trips) from the Southeast Region Headboat Survey, 1980-2013. The number of reported and estimated trips were not available in electronic format prior to 1980 .

\begin{tabular}{|c|c|c|c|}
\hline \multirow[b]{2}{*}{ Year } & \multicolumn{3}{|c|}{ Headboat fishery } \\
\hline & $\begin{array}{c}\text { Reported } \\
\text { Trips }\end{array}$ & $\begin{array}{l}\text { Estimated } \\
\text { trips }\end{array}$ & $\begin{array}{l}\text { Compliance } \\
\text { rate }\end{array}$ \\
\hline 1980 & 11,435 & 24,724 & 0.46 \\
\hline 1981 & 11,395 & 24,134 & 0.47 \\
\hline 1982 & 12,353 & 25,520 & 0.48 \\
\hline 1983 & 12,195 & 24,534 & 0.5 \\
\hline 1984 & 11,280 & 22,871 & 0.49 \\
\hline 1985 & 11,187 & 22,630 & 0.49 \\
\hline 1986 & 13,990 & 24,128 & 0.58 \\
\hline 1987 & 14,152 & 25,123 & 0.56 \\
\hline 1988 & 12,103 & 23,457 & 0.52 \\
\hline 1989 & 10,982 & 23,853 & 0.46 \\
\hline 1990 & 11,432 & 24,624 & 0.46 \\
\hline 1991 & 10,844 & 25,382 & 0.43 \\
\hline 1992 & 15,154 & 22,377 & 0.68 \\
\hline 1993 & 14,011 & 20,009 & 0.7 \\
\hline 1994 & 12,708 & 21,412 & 0.59 \\
\hline 1995 & 12,405 & 19,595 & 0.63 \\
\hline 1996 & 9,200 & 19,270 & 0.48 \\
\hline 1997 & 6,429 & 16,559 & 0.39 \\
\hline 1998 & 9,372 & 15,237 & 0.62 \\
\hline 1999 & 7,746 & 15,831 & 0.49 \\
\hline 2000 & 7,865 & 16,980 & 0.46 \\
\hline 2001 & 7,002 & 14,917 & 0.47 \\
\hline 2002 & 5,779 & 13,323 & 0.43 \\
\hline 2003 & 5,752 & 12,086 & 0.48 \\
\hline 2004 & 6,509 & 15,090 & 0.43 \\
\hline 2005 & 5,857 & 14,876 & 0.39 \\
\hline 2006 & 6,162 & 15,363 & 0.4 \\
\hline 2007 & 6,608 & 14,451 & 0.46 \\
\hline 2008 & 9,492 & 11,627 & 0.82 \\
\hline 2009 & 10,718 & 11,670 & 0.92 \\
\hline 2010 & 11,489 & 12,090 & 0.95 \\
\hline 2011 & 11,537 & 12,018 & 0.96 \\
\hline 2012 & 12,423 & 13,222 & 0.94 \\
\hline 2013 & 13,764 & 14,708 & 0.94 \\
\hline
\end{tabular}

matched trips. Because the BP's are a sample of the total catch on a trip, the number of fish measured in the BP should always be equal to or less than the number of fish reported in the CR. Port agents tend to measure up to 10 fish per species and it's unlikely that the BP would contain more fish than the $\mathrm{CR}$ for the more common species. If the number of fish measured in the $\mathrm{BP}$ is greater than the number reported caught in the CR, then an error necessarily exists in either the CR-reported catch or in the BP data.

We assumed accuracy in the BP data because they are collected by trained scientists and in recent time periods subjected to quality control procedures, implying that any discrepancy was due to error (under-reporting) in the CR. All comparisons of CR's and BP's were conducted at the level of individual vessels. It is possible that underreporting could have occurred at

\begin{tabular}{|c|c|c|c|c|c|c|}
\hline Year & Vessels & $\begin{array}{l}\text { Mean } \\
\text { anglers }\end{array}$ & $\begin{array}{l}\text { Mean maximum } \\
\text { anglers }\end{array}$ & $\begin{array}{l}\text { Mean species } \\
\text { reported }\end{array}$ & $\begin{array}{l}\text { Peak } \\
\text { month }\end{array}$ & $\begin{array}{c}\text { Mean trips } \\
\text { per year }\end{array}$ \\
\hline \multicolumn{7}{|l|}{ Carolinas } \\
\hline 1973-1983 & 58 & 32.3 & 61.0 & 5.5 & July & 2,139 \\
\hline 1984-1991 & 42 & 39.7 & 68.6 & 6.3 & July & 2,318 \\
\hline $1992-2000$ & 57 & 34.0 & 59.4 & 6.7 & June & 2,575 \\
\hline 2001-2009 & 52 & 32.8 & 54.1 & 6.1 & July & 2,455 \\
\hline 2010-2013 & 34 & 31.1 & 52.5 & 5.0 & July & 3,057 \\
\hline \multicolumn{7}{|c|}{ Georgia-North Florida } \\
\hline $1973-1983$ & 25 & 30.5 & 57.0 & 6.6 & July & 911 \\
\hline 1984-1991 & 20 & 31.5 & 56.1 & 7.7 & June & 1,370 \\
\hline $1992-2000$ & 15 & 25.8 & 61.8 & 6.5 & June & 1,150 \\
\hline $2001-2009$ & 16 & 26.3 & 45.2 & 6.7 & May & 1,148 \\
\hline 2010-2013 & 12 & 26.7 & 46.0 & 5.1 & June & 995 \\
\hline \multicolumn{7}{|l|}{ South Florida } \\
\hline 1973-1983 & 70 & 20.3 & 44.3 & 5.9 & July & 3,398 \\
\hline $1984-1991$ & 60 & 22.4 & 50.9 & 6.8 & June & 8,148 \\
\hline 1992-2000 & 75 & 20.0 & 49.7 & 5.0 & June & 6,698 \\
\hline 2001-2009 & 52 & 21.4 & 50.4 & 5.4 & June & 3,374 \\
\hline $2010-2013$ & 42 & 21.2 & 50.3 & 4.8 & June & 7,659 \\
\hline
\end{tabular}

the level of individual trips for specific vessels that would not necessarily have been identified with this approach.

We compared temporal trends in the CR-reported landings for each species with trends in the number of fish measured on the matched BP's. We assessed the degree of correlation between the species-specific number of fish measured on the BP's to those reported caught on the CR's using Spearman's rank correlation analysis. Assuming the sampling fraction and reporting accuracy were constant over time, we would expect high correlation. Discrepancies between the BP and CR trends may be indicative of misreporting of catch.

\section{Results}

The trend in estimated annual number of headboat trips throughout the SEUS has declined from about 24,000 to 15,000 between 1980 and 2013 (Table 4). Substantial differences in the numbers of reported and estimated trips between 1980 and 2008 are due to an average compliance rate of $50 \%$, which was primarily driven by very low compliance in southeast Florida. A steady decline in estimated headboat trips occurred from 1992 (22,377 trips) until 2008 (11,627 trips) but since 2008 , the number of trips has increased $\sim 25 \%$ and compliance has reached $\sim 95 \%$.

Logbook-reported data, by region and time block are summarized in Ta- ble 5. A few of the species reported most frequently in the Carolinas were black sea bass, vermilion snapper, gray triggerfish, tomtate, red porgy, and white grunt (Table 2). Two species of note, Atlantic sharpnose shark and spottail pinfish, occurred on $0 \%$ and $12 \%$ of CR's in the early time period, but $36 \%$ and $29 \%$ during 2010 to 2013. The species reported most frequently in Georgia and northeast Florida were black sea bass, vermilion snapper, gray triggerfish, red snapper, and cobia. The species reported most frequently in southeast Florida were yellowtail snapper, mutton snapper, gray snapper, white grunt and gray triggerfish. A noticeable shift in species reported through time exists among regions.

The headboat vessels in southeast Florida contribute $60 \%$ of the total number of headboat fishing trips in the SEUS, while vessels in the Carolinas contribute $27 \%$ and vessels in Georgia-northeast Florida contribute 13\%. In the Carolinas and Georgia-northeast Florida the majority of these reported trips were full day trips (54\% and $70 \%$, respectively), while in southeast Florida most were half-day trips (74\%).

The median number of fish (pooled across species) measured per trip by year and by area in DISP sampling is shown in Figure 3. The median number of fish measured per trip ranged from 9 to 47 and was typically higher in the Carolinas (range: 15-47) than 


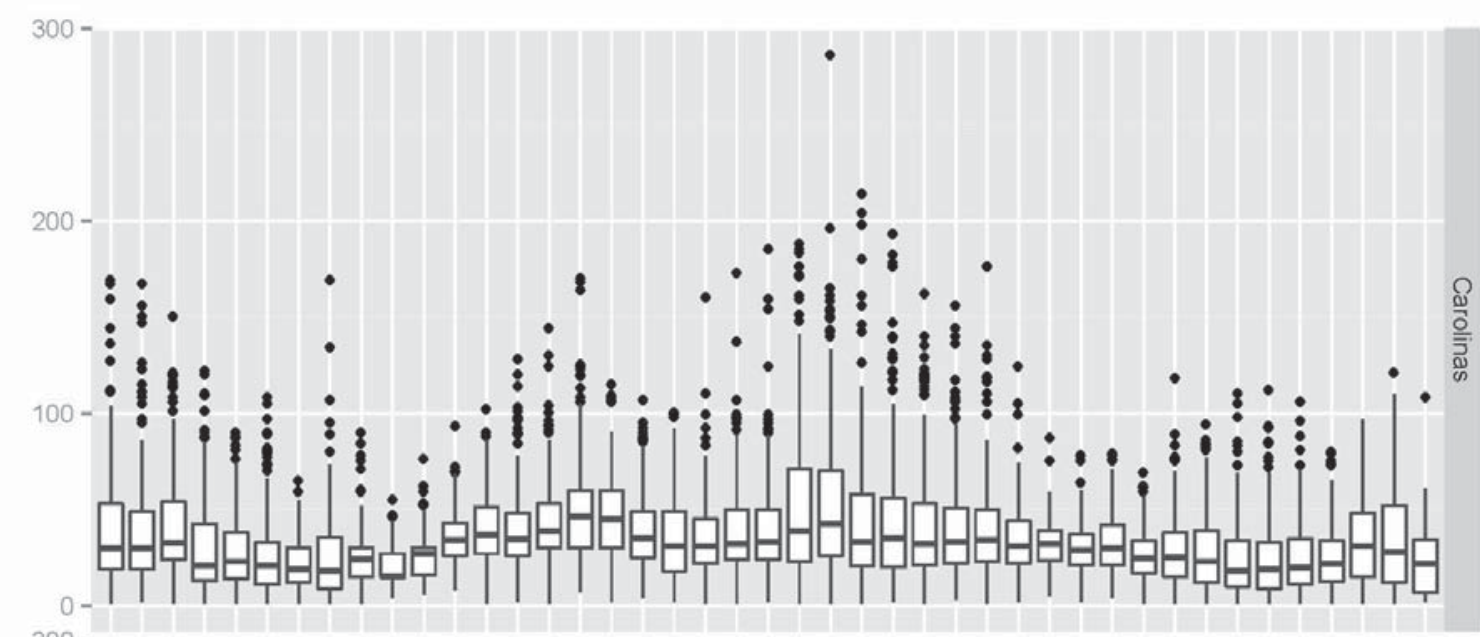
$300-$
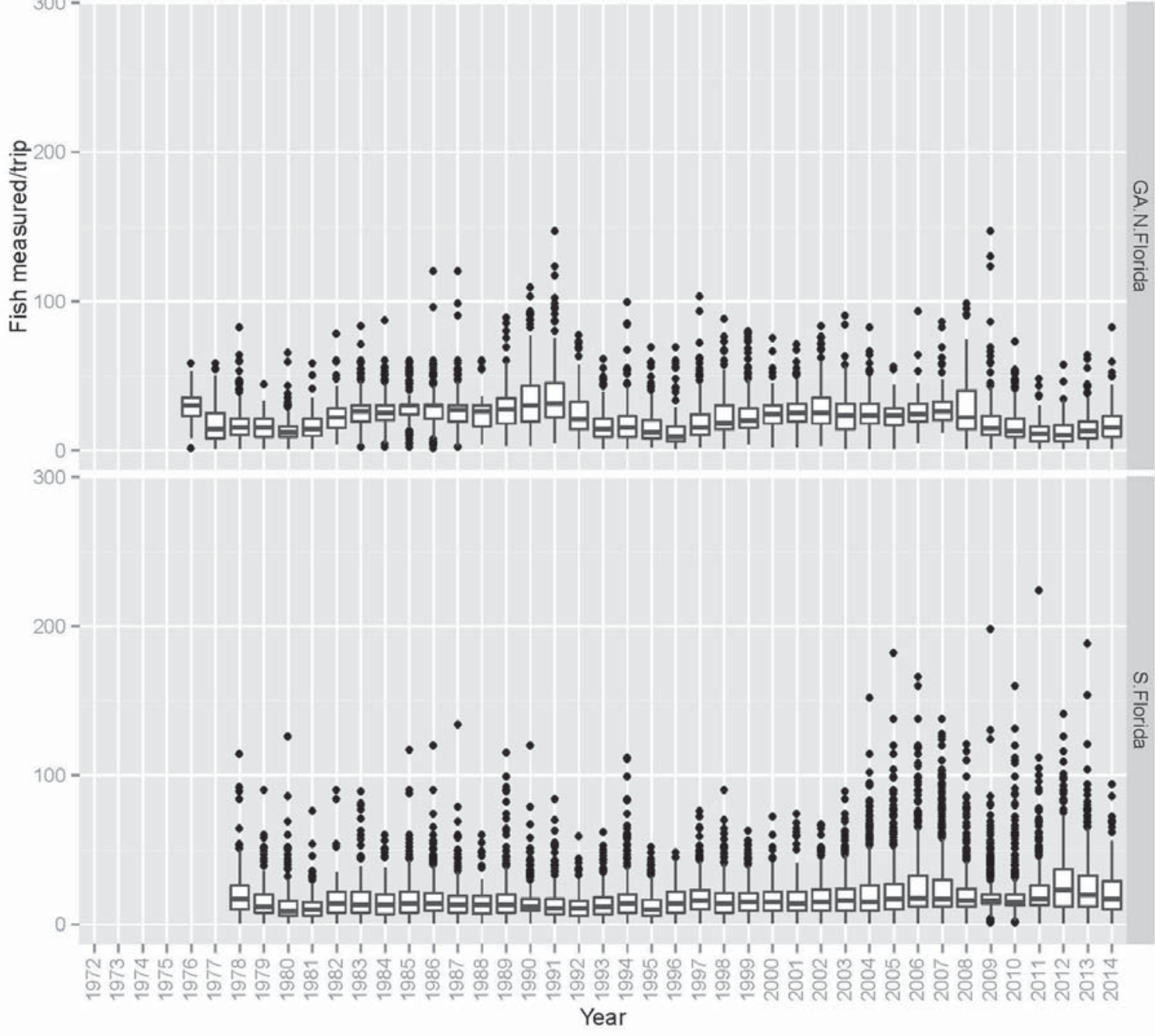

Figure 3.-Box plots representing the total number of fish (pooled across species) measured per trip by region and year. The box is the interquartile range, the horizontal line indicates the median, and the dots indicate outliers outside the 25 th and 75 th percentiles while the vertical lines represent 1.5 times the interquartile range. 
in Georgia-northeast Florida (range: 10-31) and southeast Florida (range: 9-23). Overall, the total number of fish measured was relatively consistent over time within each region.

The median number of species sampled across all trips ranged from 3 to 8 and was slightly higher in the 1980's and 1990's in the Carolinas compared to the other two regions (Fig. 4). The maximum number of species sampled also appeared to be high in the 1980's and 1990's, particularly in the Carolinas and in Georgia-northeast Florida, while the maximum number of species sampled was also high throughout the 2000's in southeast Florida. The median number of fish of each species sampled across all trips was stable among areas suggesting that SRHS sampling protocols were implemented consistently during periods of possible staff turnover and changes in the fishery (Fig. 5).

The CR "trip" field identifies trip length categorically (Fig. 6, 7). For analyses, CR trip lengths were merged into full- and half-day categories where half-day was defined as any duration less than full-day. Of the half-day trips in the Carolinas and Georgia-northeast Florida, there were rarely more than two trips in a day, while three trips per day was fairly common in southeast Florida.

Validation analyses were limited to the full-day trips for matched BP and $\mathrm{CR}$ records. There was a predominance of full-day trips in the Carolinas and Georgia-northeast Florida. Although the overall (across all regions) number of matched trips was relatively small, it was constant through time and across vessels.

Seventy-four vessels $(11.6 \%$ of the 637 vessel-area-time block combinations in the SRHS database) were flagged by at least one metric with an absolute modified z-score greater than 3.5 (Table 6). Seven species-specific metrics and three NMDS metrics flagged vessels. Of the 74 vessels flagged by at least one metric, $15 \%$ $(n=11)$ occurred in the southeast Florida region during $1972-83$. Of the 74 vessels flagged and individual trips investigated, the findings were often ex- plained by low sample sizes, inshore species assemblage influencing the NMDS results, or species metrics with above-average catches.

BP's represent a subsample of the CR's and therefore should always have fewer fish. If BP's have more fish than CR's, this indicates that not all fish were reported in the CR's. Across regions, underreporting (fewer fish reported on CR's than on matched BP's) was evident for only a small proportion of vessels. When underreporting was observed, the number of "missed fish" was very small across years for all regions (Fig. 8-10).

Species such as red snapper and gray triggerfish had relatively few and small discrepancies between the BP's and CR's (Fig. 11, 12). For other commonly encountered species the number of fish missed (underreported) on the CR's (based on comparison to the BP's) was also a very small proportion of the reported catch, and those instances occurred sporadically across the time series and the three regions.

For rarer species such as littlehead porgy, Calamus proridens; and ocean triggerfish, Canthidermis sufflamen, the proportion of missed fish in the Carolinas and Georgia-northeast Florida was relatively low and similar to that for well-sampled species in those areas (Fig. 13, 14). However, in southeast Florida there tended to be more missed fish for less common species or species that were difficult to identify to species (e.g., porgy).

Species-specific correlations between reported landings and numbers sampled on the BP's were typically highest in regions where the focal species occurs in highest abundance (and is therefore most commonly caught). Species-specific time series of landings in the CR's correlated positively with the number sampled in the BP's, although correlations tended to be weaker in southeast Florida than in the Carolinas and Georgia-northeast Florida (Fig. 15).

\section{Discussion}

We believe this analysis of potential misreporting supports the conclusion that the SRHS data are largely accurate and unbiased, but remain unvalidated. The detection of outliers and patterns in the computed metrics was dependent to some extent on the choice of spatial and temporal strata. The methods used here would not detect misreported data that were reasonably consistent with accurate self-reported data. However, this type of misreporting would likely have negligible effects on resulting data products (e.g., landings and indices of abundance), which rely on the assumption that the central tendencies are unbiased. Our outlier analysis was designed to detect potentially misreported data that are inconsistent with the bulk of the database. For this approach, the identification of outliers was based on the modified z-score methodology Iglewicz and Hoaglin (1993) recommended, a threshold value of 3.5 (adopted here), while Hammer et al. (2010) used a threshold of 3 to delineate outliers. Various thresholds lower than $3.5(3.25,3,2.75)$ were explored here and, as expected, resulted in increases in flagged vessels. These vessels and the associated trips that were examined, indicate that vessels with a modified $\mathrm{z}$-score less than 3.5 were trips in the outer edge of the median, but were not considered extreme.

The analyses focusing on BP data were limited to a subsample of trips for which the data could be matched to logbook (CR) data. It was only possible to match BP and CR data for fullday trips (i.e., trips on days when the vessel made only one trip, regardless of trip type). This resulted in a subsample of trips in the Carolinas and in Georgia-northeast Florida because full-day trips are common in these regions, where more time is needed to reach desired fishing grounds further offshore. In contrast, the matched trips were only a small proportion of the total trips in southeast Florida, where there was a predominance of partialday trips due to the region's close proximity to deeper waters.

A spatial shift from full-day trips in the north to predominately partialday trips in the south may help explain 

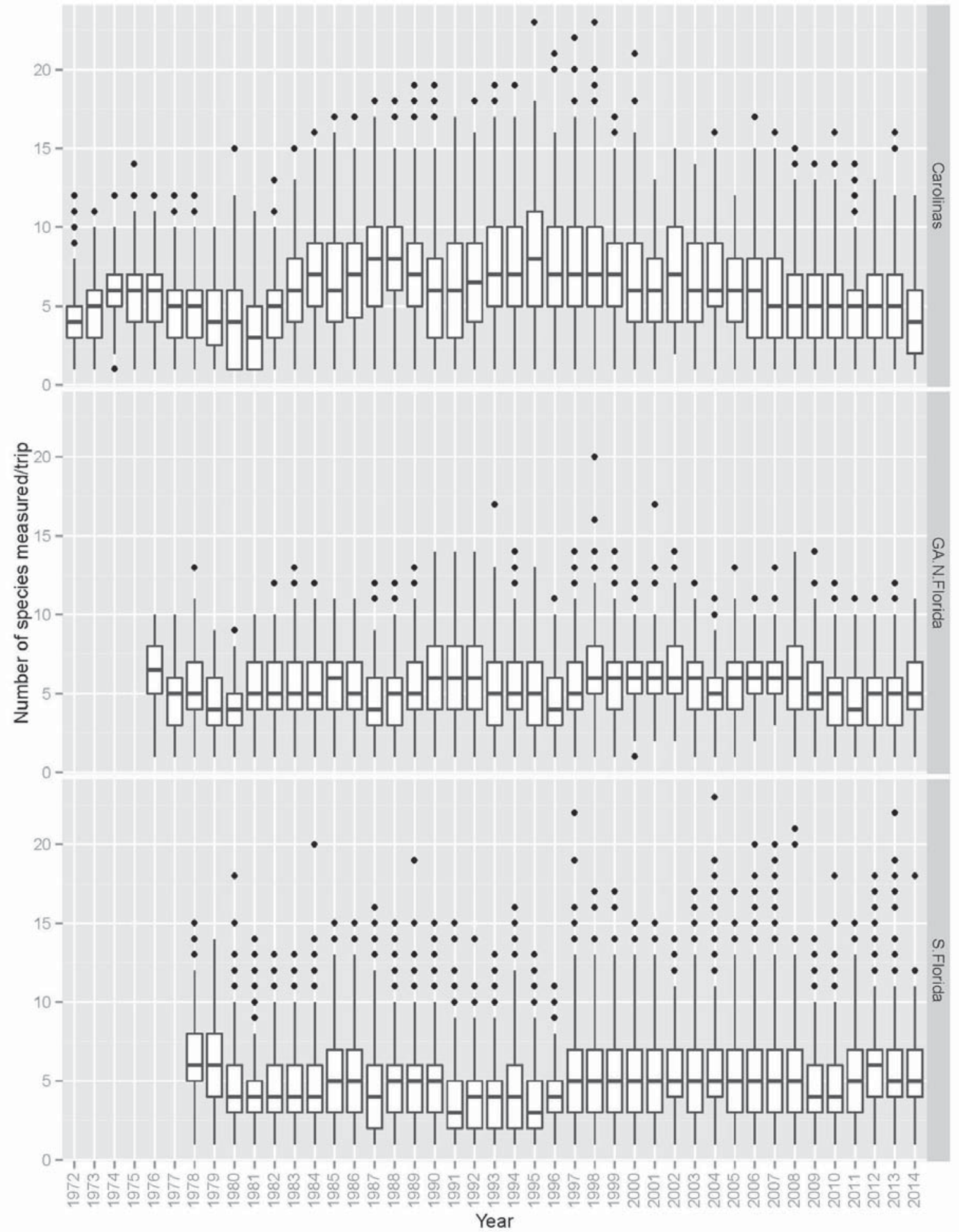

Figure 4.-Box plots representing the median number of species measured per trip by region and year. The box is the interquartile range, the horizontal line indicates the median, and the dots indicate outliers outside the 25th and 75 th percentiles while the vertical lines represent 1.5 times the interquartile range. 

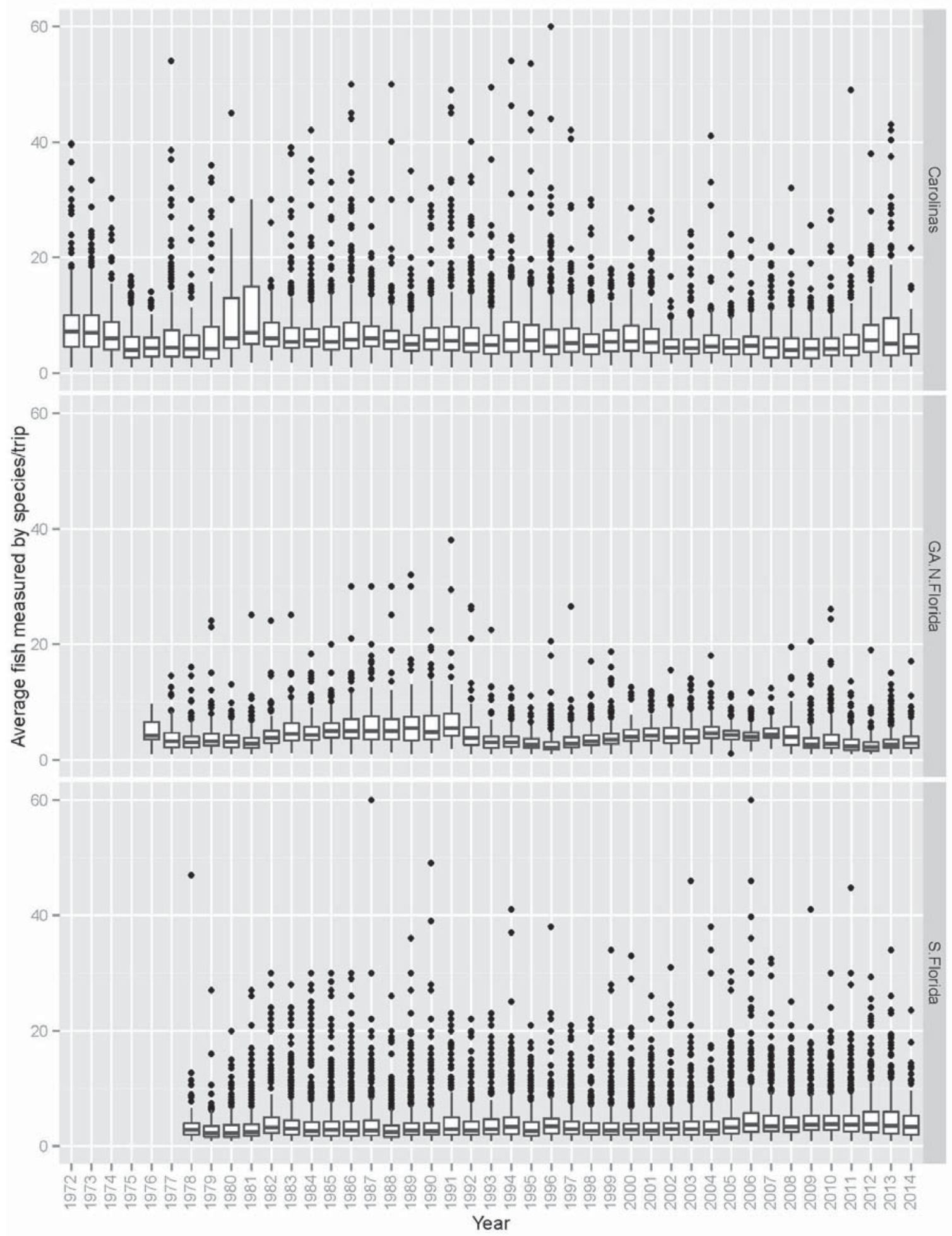

Figure 5.-Box plots representing the median number of fish measured per trip by region and year. The box is the interquartile range, the horizontal line indicates the median, and the dots indicate outliers outside the 25 th and 75 th percentiles while the vertical lines represent 1.5 times the interquartile range. 
Table 6. - Flagged vessels by modified z-score. Column designations are: Region (1=Carolinas, 2=Ga-nFL, 3=sFL), n.trips=Number of trips, yts.m=yellowtail snapper mean catch, vs.m=vermilion snapper mean catch, tom.m=tomtate mean catch, $\mathrm{ms} . \mathrm{m}=$ mutton snapper mean catch, wg.m=white grunt mean catch, $\mathrm{kwporgy} \cdot \mathrm{m}=\mathrm{key}$ west porgy mean catch, sdprch.v=sand perch variance, $\mathbf{z}$ sp $25=$ NMDS presence/absence top 25 species, $z$ sp_all=NMDS presence/absence all species, $z$ cpue all=NMDS catch rate all species. Bold highlights the values that are greater than $\mathbf{3 . 5}$ (significant outliers).

\begin{tabular}{|c|c|c|c|c|c|c|c|c|c|c|c|c|}
\hline Year & Region & n.trips & yts.m & vs.m & tom.m & ms.m & wg.m & kwporgy.m & sdprch.v & z_sp_25 & z_sp_all & z_cpue_all \\
\hline $1972-1983$ & 1 & 1 & & & & & & & & 4.5 & 2.5 & 2.2 \\
\hline $1972-1983$ & 1 & 1 & & & & & 0.1 & & & 4.6 & 2.7 & 1.9 \\
\hline $1972-1983$ & 2 & 1 & & 0.1 & & & & & & 4.2 & 2.5 & 1.2 \\
\hline $1972-1983$ & 3 & 1 & 1.1 & & 1.1 & 0.5 & & 1.5 & & 4.1 & 3.1 & 2.0 \\
\hline $1972-1983$ & 3 & 1 & & & 0.1 & -0.2 & & & & 4.8 & 2.8 & 1.3 \\
\hline $1972-1983$ & 3 & 1 & & & & & 0.3 & & & 6.3 & 4.0 & 2.5 \\
\hline $1972-1983$ & 3 & 1 & & 0.7 & & & & & & 5.5 & 4.1 & 1.5 \\
\hline $1992-2000$ & 3 & 1 & -1.5 & & & -0.6 & & & & 5.9 & 6.8 & 3.4 \\
\hline $1972-1983$ & 2 & 2 & & & & & & & & 6.3 & 4.0 & 2.4 \\
\hline $1984-1991$ & 3 & 2 & & & & 0.9 & & & & 7.0 & 4.0 & 2.5 \\
\hline $1992-2000$ & 1 & 2 & & & & & & & & 5.1 & 4.4 & 1.9 \\
\hline 1984-1991 & 3 & 3 & & 0.7 & 0.3 & & & & & 4.6 & 3.0 & 1.8 \\
\hline $2001-2009$ & 1 & 3 & & & & & & & & 7.1 & 5.6 & 3.2 \\
\hline 2001-2009 & 2 & 3 & & 0.2 & & & & & & 7.9 & 5.0 & 2.7 \\
\hline 2010-2013 & 2 & 3 & & 1.2 & & & & & & 304.1 & 4.1 & 4.8 \\
\hline 2010-2013 & 2 & 3 & & & & 0.2 & & & & 303.9 & 4.5 & 3.5 \\
\hline $1984-1991$ & 3 & 4 & -0.3 & & & -0.4 & & & & 3.9 & 1.2 & 1.6 \\
\hline $1984-1991$ & 3 & 5 & 0.2 & & & 1.2 & & & & 4.0 & 1.9 & 1.0 \\
\hline $1984-1991$ & 3 & 6 & 0.1 & & 0.2 & 0.2 & 0.0 & & & 3.6 & 2.2 & 1.6 \\
\hline $1972-1983$ & 3 & 7 & & & & 0.2 & & & & 5.7 & 3.3 & 2.1 \\
\hline $1972-1983$ & 3 & 7 & & & & & & & & 8.2 & 4.8 & 3.1 \\
\hline $1984-1991$ & 3 & 7 & 0.9 & & -1.0 & 0.4 & -1.0 & & & 4.0 & 2.5 & 1.6 \\
\hline $1992-2000$ & 2 & 7 & & & 0.4 & & & & & 5.6 & 7.3 & 3.4 \\
\hline $1992-2000$ & 3 & 7 & 0.3 & & & & & & & 6.2 & 7.0 & 2.1 \\
\hline 2010-2013 & 2 & 7 & & & & -0.3 & & & & 304.7 & 4.1 & 3.0 \\
\hline $1972-1983$ & 3 & 8 & & 0.5 & & & -0.4 & & & 4.0 & 1.7 & 1.7 \\
\hline $2010-2013$ & 2 & 8 & & & & & & & & 658.8 & 10.3 & 4.9 \\
\hline $1992-2000$ & 1 & 9 & & & & & & & & 5.3 & 4.0 & 1.8 \\
\hline 2001-2009 & 3 & 9 & 0.6 & & & 0.3 & -0.8 & & & 6.0 & 4.6 & 0.9 \\
\hline 2001-2009 & 3 & 9 & 0.1 & & & -0.4 & 0.2 & 0.7 & & 4.2 & 5.1 & 1.0 \\
\hline $1972-1983$ & 3 & 10 & & 0.1 & & -0.1 & & 0.0 & & 5.7 & 3.3 & 1.9 \\
\hline $2010-2013$ & 3 & 10 & 0.2 & 0.8 & & 0.4 & & & & 7.2 & 2.8 & 1.3 \\
\hline 2001-2009 & 2 & 12 & & & & & -0.7 & & & 7.6 & 3.1 & 1.8 \\
\hline $2010-2013$ & 3 & 12 & -1.1 & & & -0.7 & & & & 11.9 & 6.1 & 4.7 \\
\hline $1984-1991$ & 2 & 14 & & 1.6 & -0.8 & & & & & 4.8 & 1.4 & 1.6 \\
\hline $2001-2009$ & 1 & 15 & & & & & & & & 3.5 & 2.2 & 2.4 \\
\hline $1984-1991$ & 2 & 16 & & -0.5 & 0.0 & & & & 0.3 & 5.1 & 1.6 & 0.8 \\
\hline $1992-2000$ & 2 & 16 & & 0.1 & -1.0 & & -0.1 & & & 3.9 & 5.0 & 3.2 \\
\hline 2001-2009 & 2 & 16 & & 0.4 & & & -0.8 & & & 4.1 & 3.2 & 1.0 \\
\hline $1984-1991$ & 1 & 17 & & & & & & & -0.4 & 6.5 & 3.2 & 2.2 \\
\hline 1984-1991 & 3 & 25 & 0.3 & & & -0.7 & -1.5 & -0.3 & & 3.6 & 2.0 & 0.4 \\
\hline $1972-1983$ & 3 & 26 & & & 0.0 & & 0.1 & -0.6 & & 4.6 & 3.4 & 1.0 \\
\hline $1972-1983$ & 3 & 33 & -0.7 & & & -0.9 & -0.3 & 0.2 & & 3.5 & 1.4 & 0.6 \\
\hline 2010-2013 & 2 & 35 & & & -1.1 & & 0.4 & & & 303.3 & 3.0 & 2.4 \\
\hline $2001-2009$ & 1 & 40 & & & & & & & & 3.8 & 2.6 & 1.0 \\
\hline $1972-1983$ & 1 & 57 & & & & & & & & 4.5 & 2.5 & 2.2 \\
\hline 2001-2009 & 1 & 62 & & & & & & & & 5.8 & 3.4 & 1.5 \\
\hline $1992-2000$ & 1 & 78 & & & & & & & & 3.6 & 2.5 & 0.6 \\
\hline $1972-1983$ & 2 & 82 & & -0.3 & 0.3 & & & 3.8 & & 0.3 & 0.4 & -0.7 \\
\hline $1992-2000$ & 1 & 92 & & & & & & & & 4.9 & 3.1 & 1.0 \\
\hline $2010-2013$ & 1 & 95 & & & -0.7 & & 0.1 & & & 3.7 & 3.2 & 0.9 \\
\hline 2010-2013 & 3 & 126 & -0.2 & 0.1 & & 0.4 & & & & 5.7 & 2.1 & 1.5 \\
\hline $2010-2013$ & 1 & 128 & & -4.2 & & & & & & 2.4 & 2.7 & 0.2 \\
\hline $1984-1991$ & 2 & 132 & 0.7 & 0.5 & 0.8 & 0.6 & 4.6 & 0.4 & 0.8 & -0.4 & -0.2 & -0.5 \\
\hline 2010-2013 & 1 & 153 & & & & & & & & 3.7 & 4.0 & 1.2 \\
\hline $1992-2000$ & 1 & 163 & & 0.2 & & 3.6 & 0.6 & 0.7 & & 0.0 & -0.1 & -0.4 \\
\hline 1984-1991 & 1 & 213 & & & -0.7 & & & & & 4.8 & 1.8 & 0.1 \\
\hline $2001-2009$ & 1 & 263 & & & & & & & & 3.6 & 2.3 & 0.8 \\
\hline 2010-2013 & 1 & 272 & & -4.6 & -0.6 & & 0.1 & -0.5 & 0.4 & -0.4 & -0.2 & -0.5 \\
\hline $1992-2000$ & 2 & 289 & & 0.6 & & & & & & 2.5 & 4.0 & 1.0 \\
\hline $1984-1991$ & 1 & 298 & & & -1.3 & & & & & 7.8 & 3.0 & 3.9 \\
\hline $1992-2000$ & 1 & 299 & & 1.4 & & & & & & 3.6 & 2.6 & 0.5 \\
\hline $1972-1983$ & 3 & 362 & 0.3 & 0.4 & 0.7 & 0.1 & 0.1 & 0.5 & -5.5 & 0.0 & 0.2 & -0.7 \\
\hline 1984-1991 & 2 & 377 & 0.1 & -0.3 & 0.2 & 1.7 & 5.0 & 0.0 & 0.6 & -0.8 & -0.7 & -0.5 \\
\hline 2010-2013 & 1 & 387 & 4.6 & -0.6 & -0.1 & & 0.0 & 0.0 & & 0.0 & -0.1 & -0.6 \\
\hline $2010-2013$ & 1 & 406 & 4.6 & -0.5 & 0.5 & 2.0 & 0.2 & 0.3 & 0.0 & 0.0 & -0.4 & -1.2 \\
\hline 2010-2013 & 1 & 455 & & & & & 0.0 & & & 5.3 & 5.1 & 1.2 \\
\hline $1984-1991$ & 2 & 459 & -0.3 & 0.1 & -0.3 & -0.4 & 3.8 & -0.3 & 1.6 & -0.4 & -0.3 & -0.2 \\
\hline $2010-2013$ & 3 & 542 & 0.0 & & & -0.4 & 0.5 & 0.3 & & 4.0 & 0.8 & 0.2 \\
\hline 1984-1991 & 1 & 823 & & -2.1 & -1.5 & 4.6 & -1.0 & -1.2 & 0.0 & -0.5 & 0.3 & 0.0 \\
\hline $2001-2009$ & 1 & 968 & 0.7 & 0.1 & 1.3 & 7.0 & 0.4 & 0.4 & 1.1 & 0.0 & -0.4 & -0.6 \\
\hline 2001-2009 & 2 & 1,696 & 0.3 & -0.7 & -0.7 & 0.5 & 0.0 & 3.8 & & -0.4 & -0.6 & -0.4 \\
\hline 1984-1991 & 2 & 2,141 & 0.0 & -0.7 & -3.6 & -0.2 & & 0.0 & & 0.4 & -0.1 & 0.2 \\
\hline $1984-1991$ & 1 & 2,143 & & -0.3 & 0.7 & & -1.6 & & & 6.4 & 2.9 & 0.3 \\
\hline
\end{tabular}




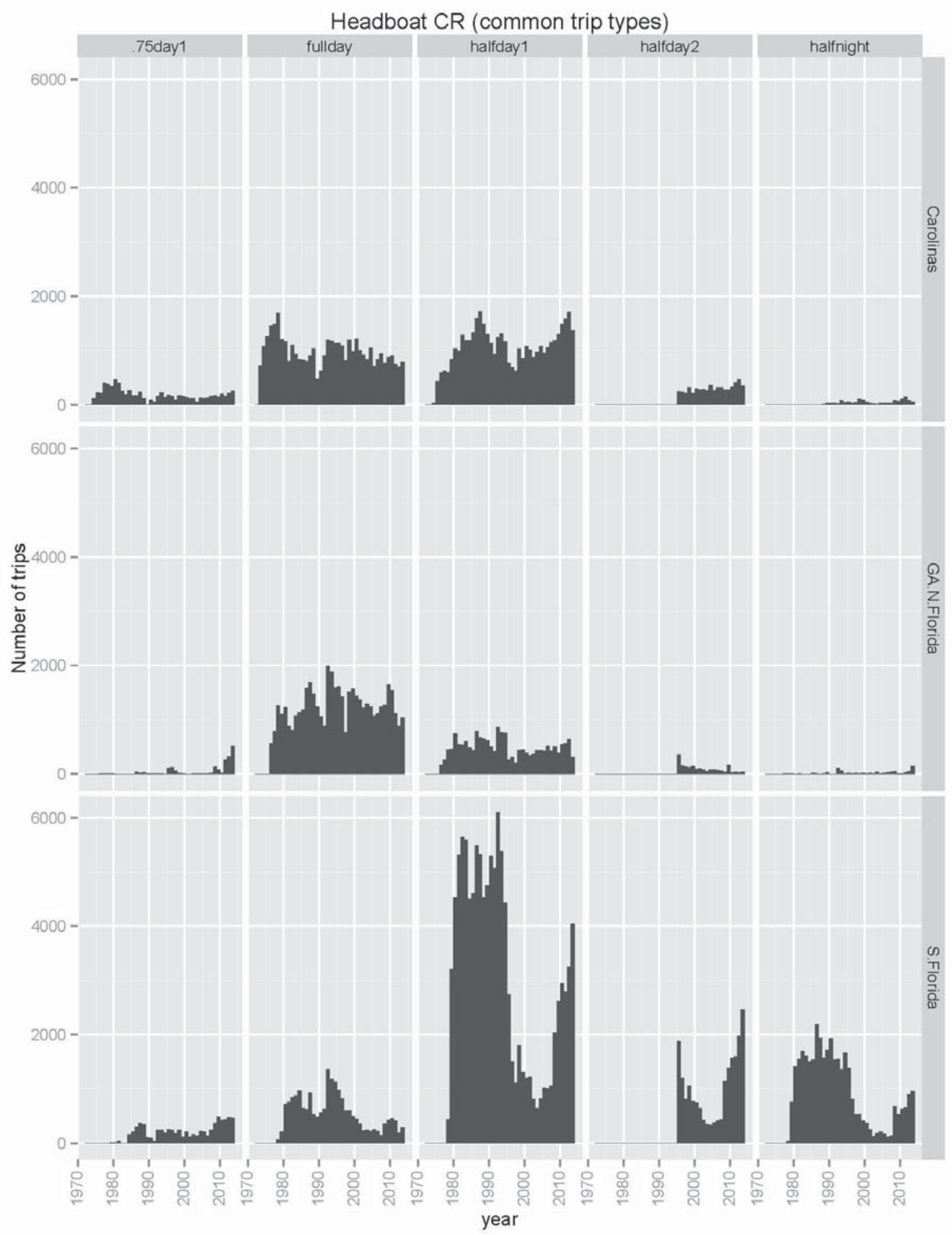

Figure 6.-Number of common trip types in southeast U.S. Atlantic headboat fishery catch records by year and region. "75day 1 " represents a three-quarter-day trip approximately $6 \mathrm{~h}$ in length, "fullday" represents an approximate $8 \mathrm{~h}$ trip, "halfdayl" represents an approximate $4 \mathrm{~h}$ morning trip, "halfday2" represents an approximate $4 \mathrm{~h}$ afternoon trip, "halfnight" represents an approximate $4 \mathrm{~h}$ night trip. 


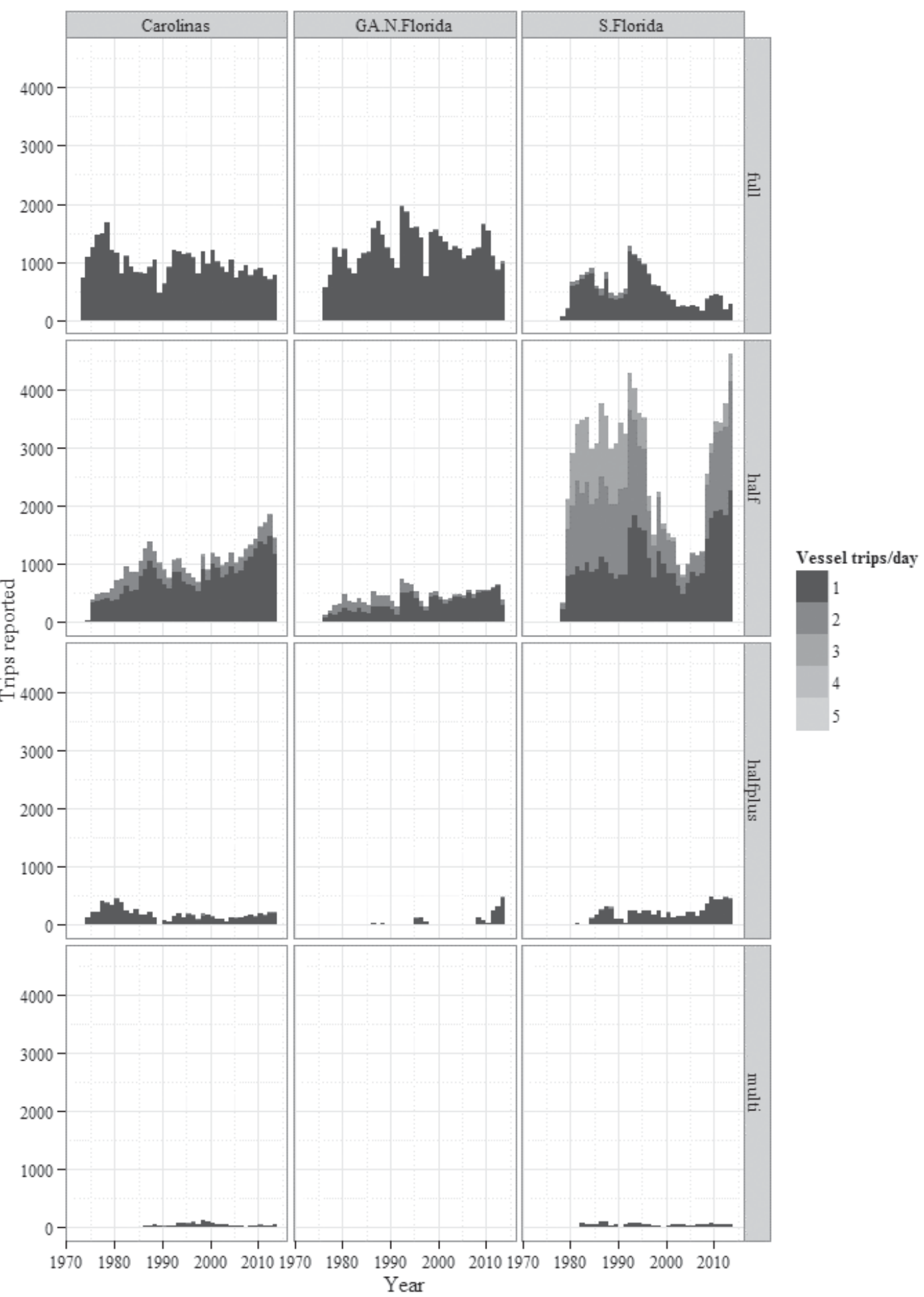

Figure 7.-Number of all trip types in the southeast U.S. Atlantic headboat fishery catch records by year and region. "Full" represents an approximate $8 \mathrm{~h}$ trip, "half" represents an approximate $4 \mathrm{~h}$ morning trip (dropped afternoon trips), "halfplus" represents a three-quarter-day trip approximately $6 \mathrm{~h}$ in length, "multi" represents a trip longer than $8 \mathrm{~h}$. 


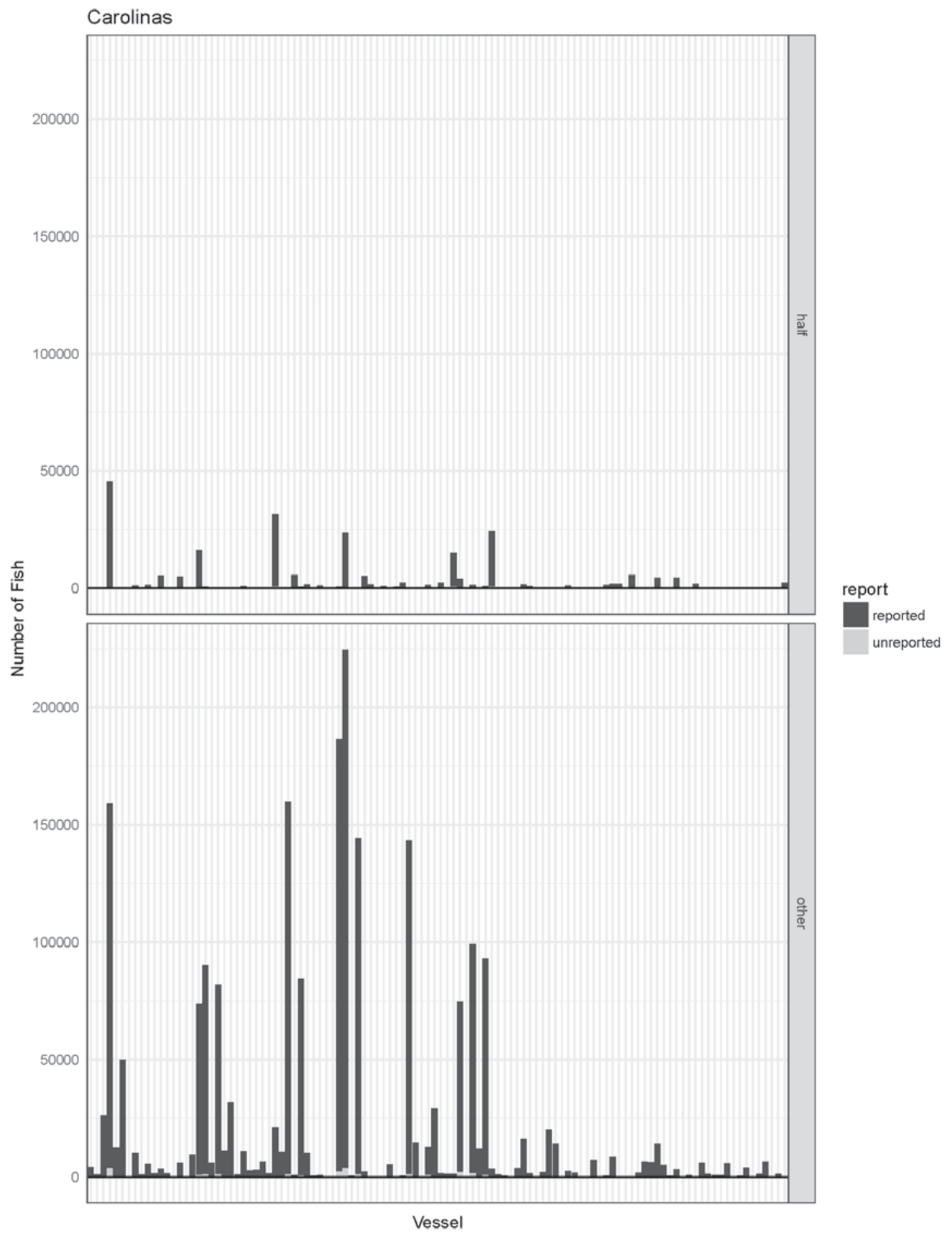

Figure 8.-Number of fish sampled but not reported on the logbook in the Carolinas, by vessel, using matched trips over all years ("half" and "other" trips, i.e., all trips other than "half-day"). The grey bar is the total number of fish reported on CR's for the matched trips. The black bar is the difference between the total number of fish reported on BP's and the total number of fish reported on CR's for the matched trips, and is only shown if that difference is positive. For confidentiality vessels are unidentified. 


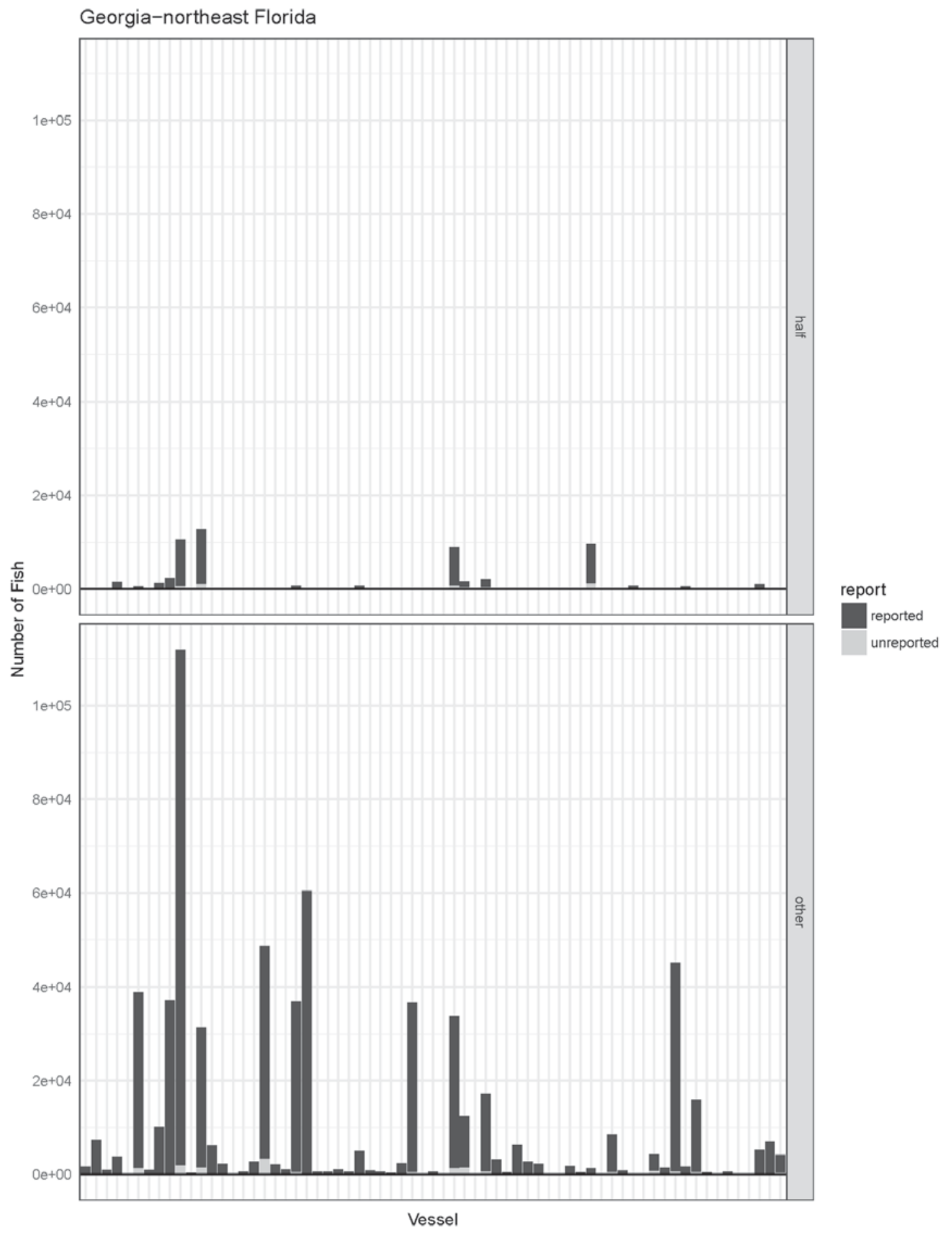

Figure 9.-Number of fish sampled but not reported on the logbook in Georgia-northeast Florida, by vessel, using matched trips over all years ("half" and "other" trips, i.e., all trips other than "half-day"). The grey bar is the total number of fish reported on CR's for the matched trips. The black bar is the difference between the total number of fish reported on BP's and the total number of fish reported on CR's for the matched trips, and is only shown if that difference is positive. For confidentiality vessels are unidentified. 


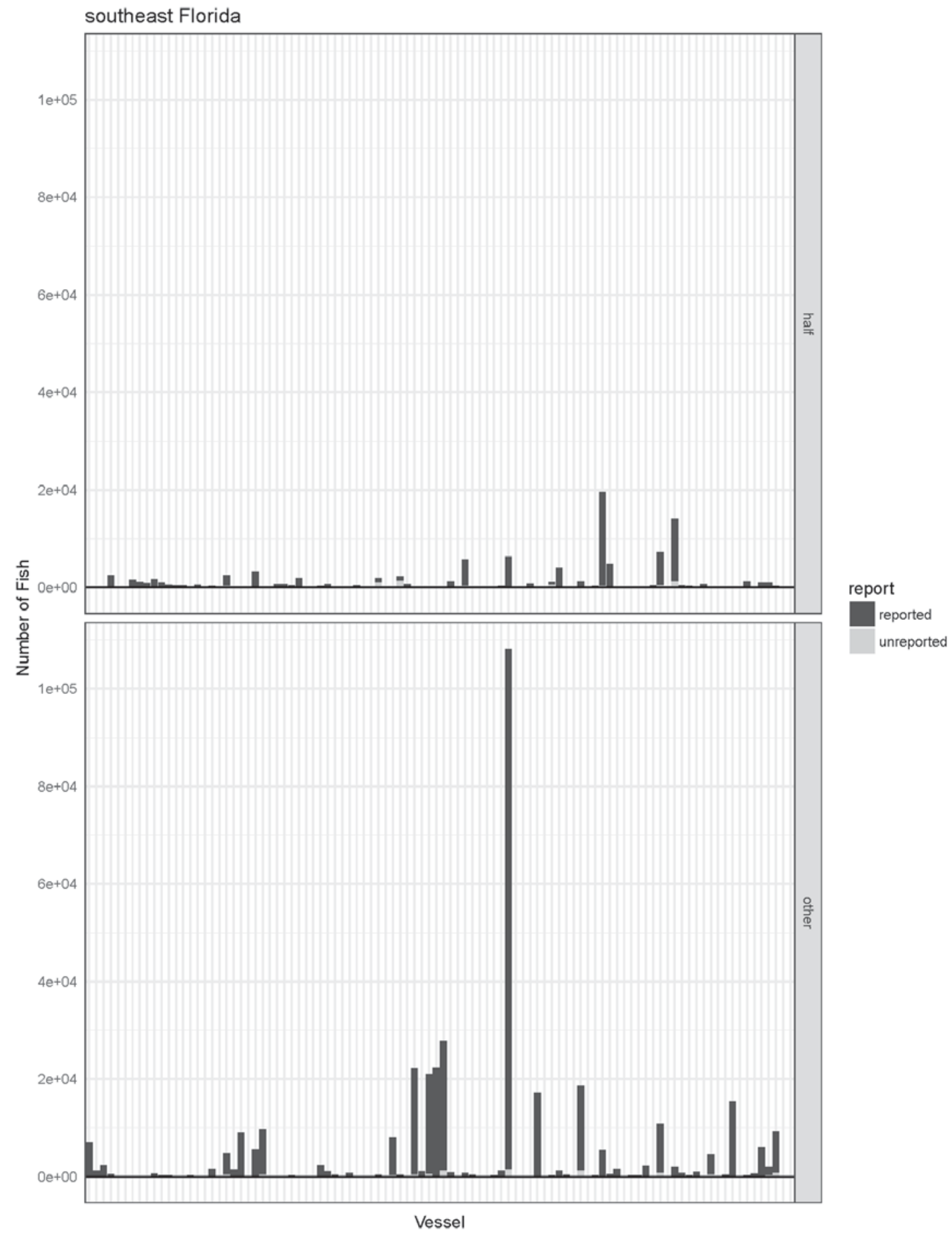

Figure 10.-Number of fish sampled but not reported on the logbook in southeast Florida, by vessel, using matched trips over all years ("half" and "other" trips, i.e., all trips other than "half-day"). The grey bar is the total number of fish reported on CR's for the matched trips. The black bar is the difference between the total number of fish reported on BP's and the total number of fish reported on CR's for the matched trips, and is only shown if that difference is positive. For confidentiality vessels are unidentified. 


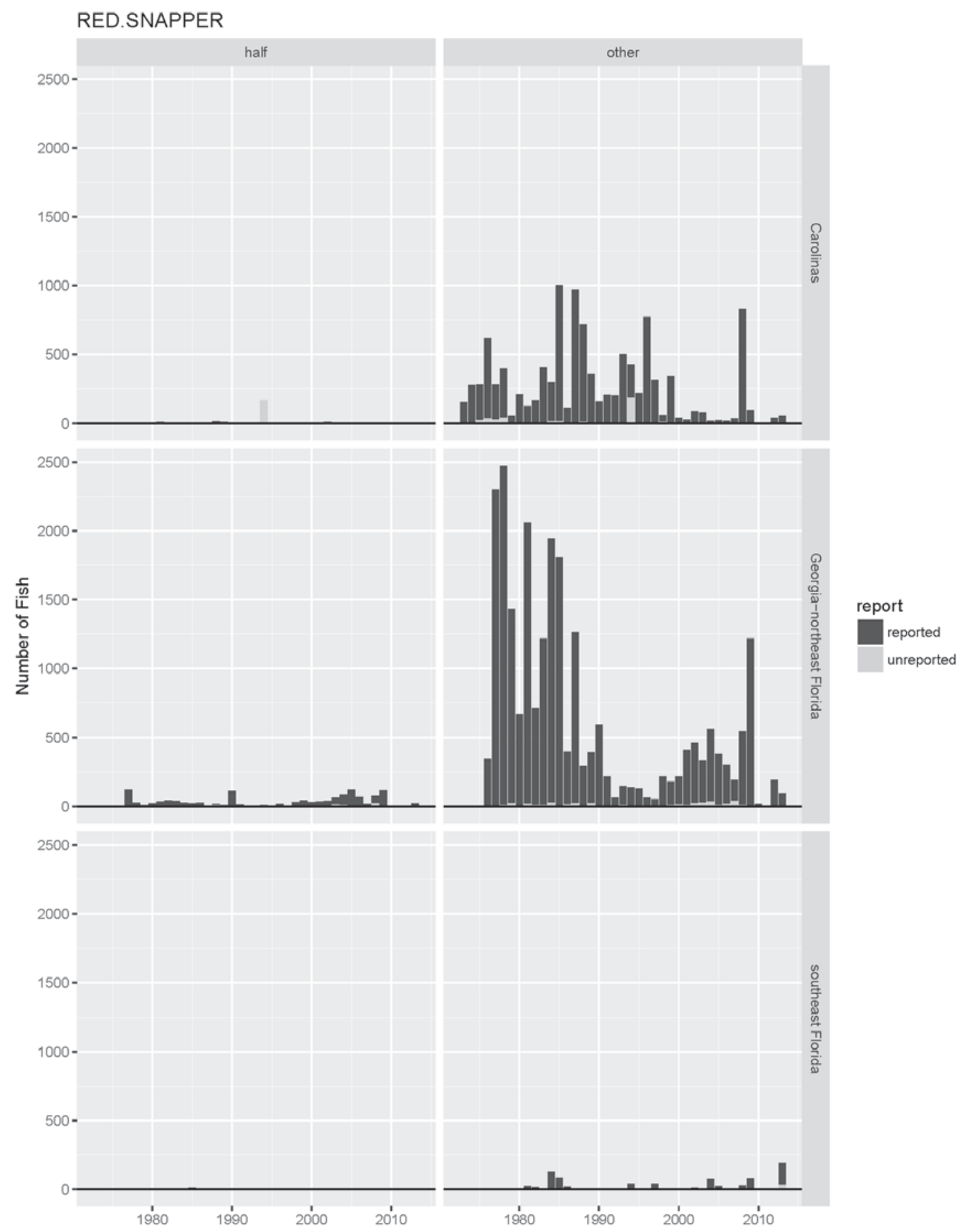

Figure 11.- The number of missed red snapper reported on the logbook by year in each region by all vessels using matched trips ("half" and "other" trips, i.e., all trips other than "half-day"). The grey bar is the total number of fish reported on CR's for the matched trips. The black bar is the difference between the total number of fish reported on BP's and the total number of fish reported on CR's for the matched trips, and is only shown if that difference is positive. For confidentiality vessels are unidentified. 


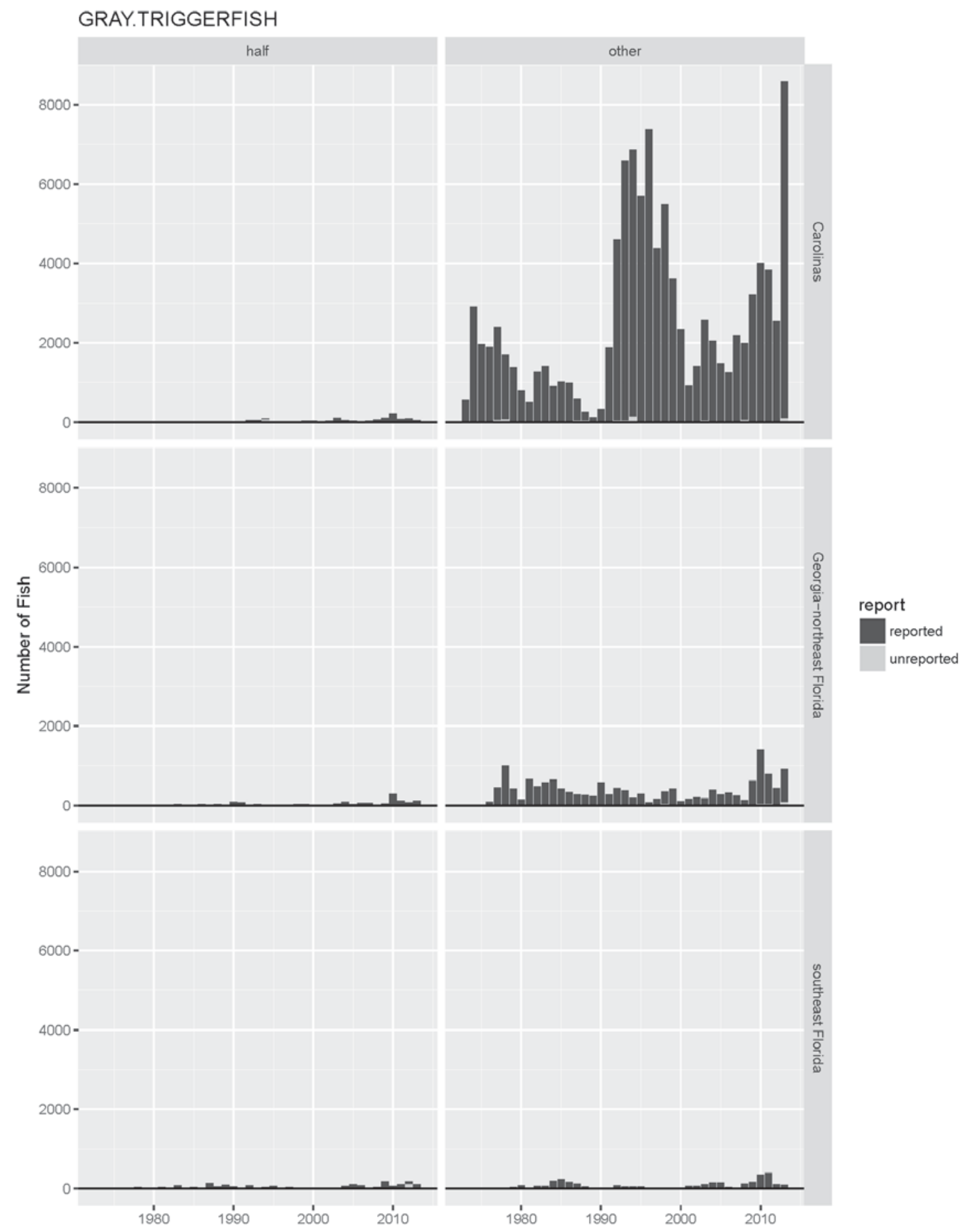

Figure 12.- The number of missed gray triggerfish reported on the logbook by year in each region by all vessels using matched trips ("half" and "other" trips, i.e., all trips other than "half-day"). The grey bar is the total number of fish reported on CR's for the matched trips. The black bar is the difference between the total number of fish reported on BP's and the total number of fish reported on CR's for the matched trips, and is only shown if that difference is positive. For confidentiality vessels are unidentified. 


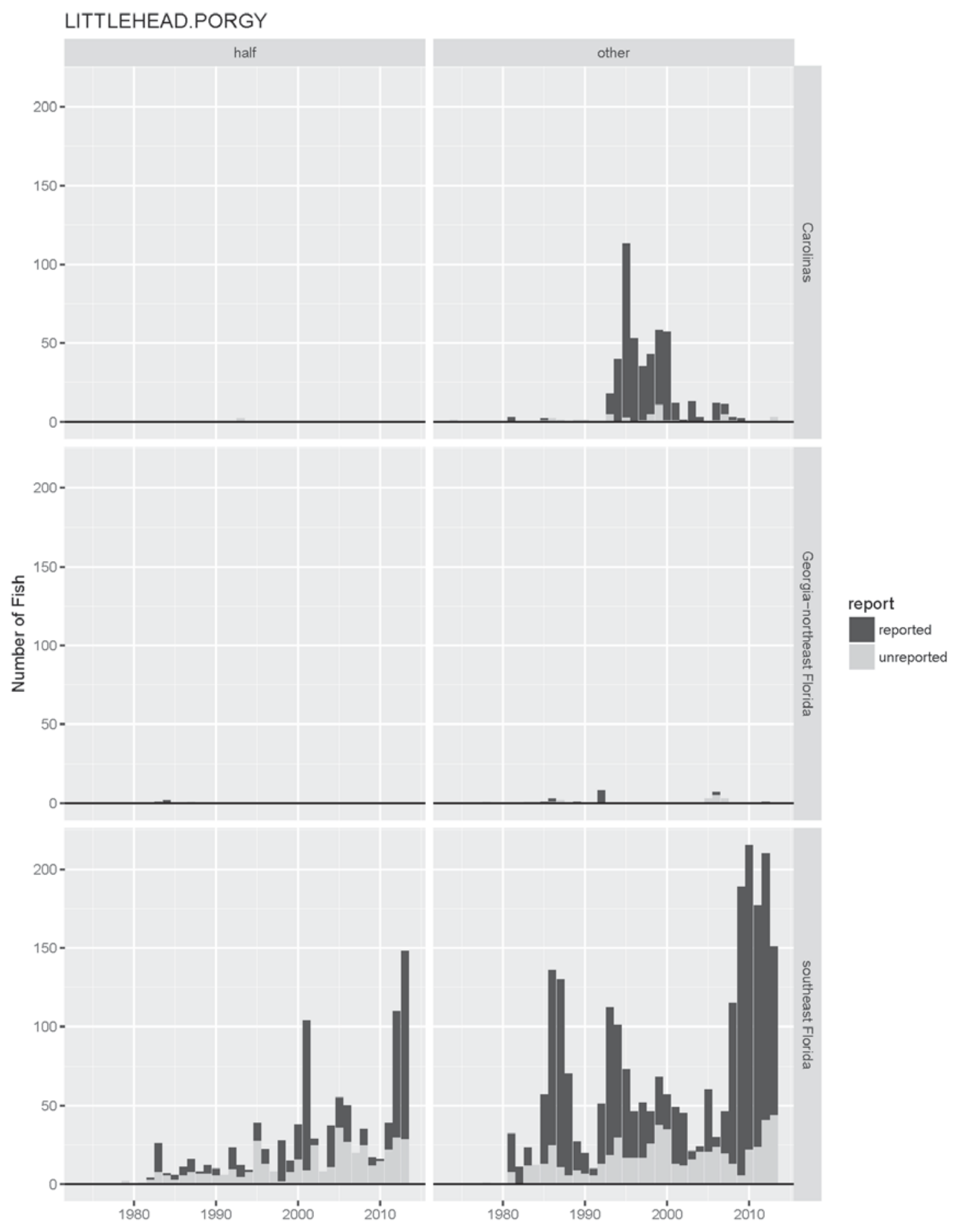

Figure 13. - The number of missed littlehead porgy reported on the logbook by year in each region by all vessels using matched trips ("half" and "other" trips, i.e., all trips other than "half-day"). The grey bar is the total number of fish reported on CR's for the matched trips. The black bar is the difference between the total number of fish reported on BP's and the total number of fish reported on CR's for the matched trips, and is only shown if that difference is positive. For confidentiality vessels are unidentified. 


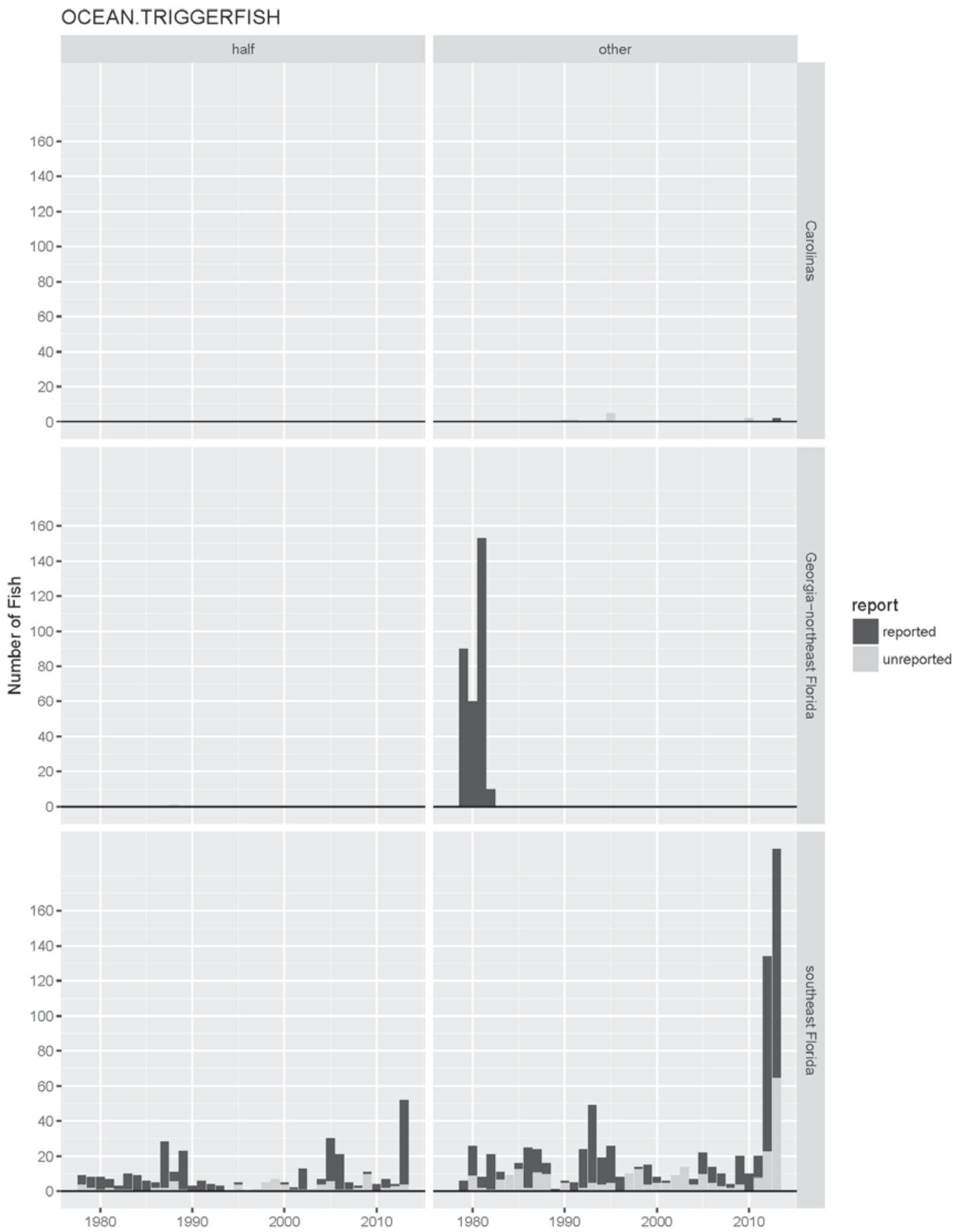

Figure 14. - The number of missed ocean triggerfish reported on the logbook by year in each region by all vessels using matched trips ("half" and "other" trips, i.e., all trips other than"half-day"). The grey bar is the total number of fish reported on CR's for the matched trips. The black bar is the difference between the total number of fish reported on BP's and the total number of fish reported on CR's for the matched trips, and is only shown if that difference is positive. For confidentiality vessels are unidentified. 


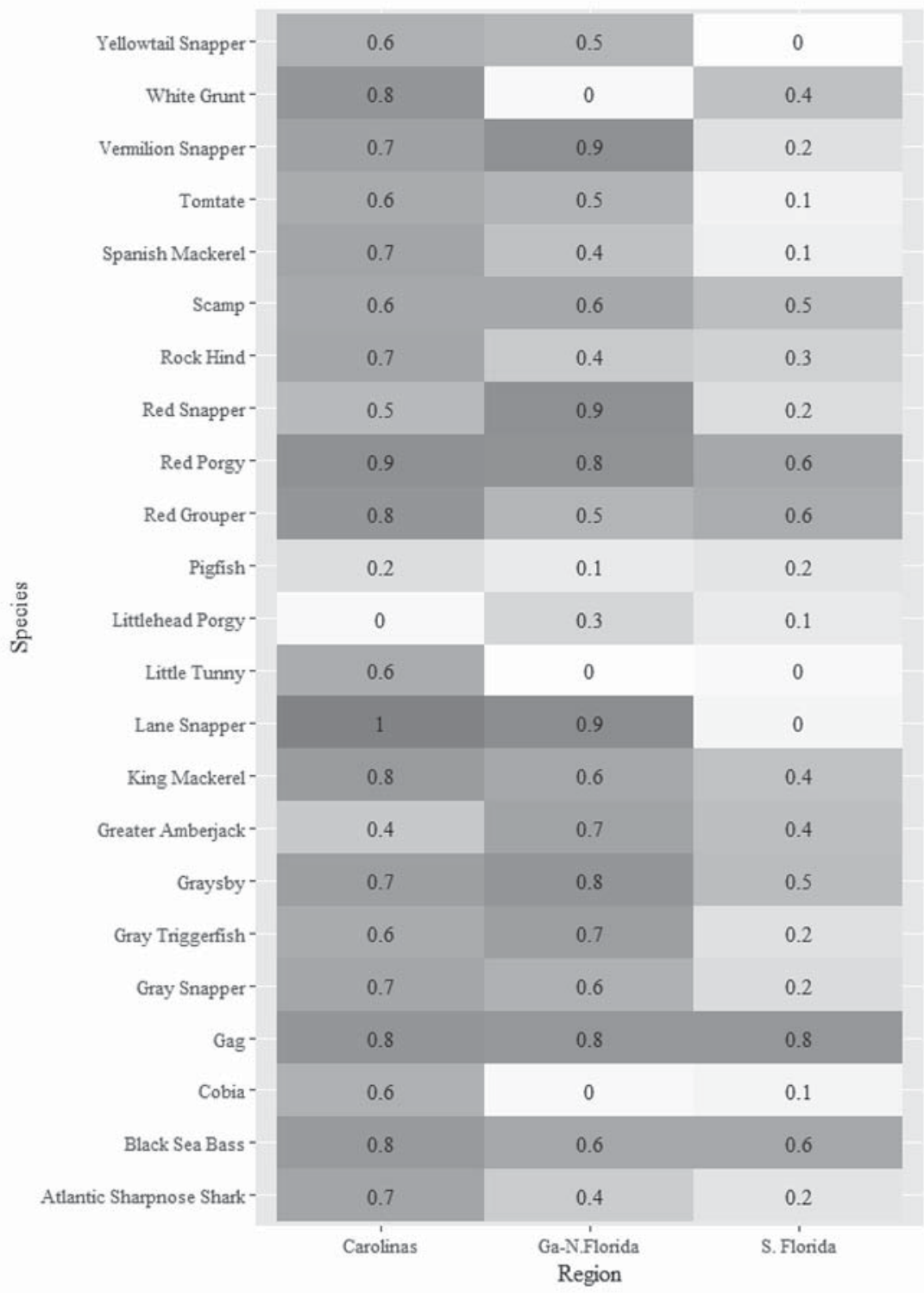

Figure 15.- Spearman rank correlation coefficient (rho) between landed (CR's) compared to the number sampled (BP's) by year and region for species in the southeast U.S. Atlantic headboat fishery.

the slight decrease in number of species sampled in southeast Florida due to the decrease in actual fishing time. Additionally, because there are few full-day trips in southeast Florida, it is possible that the single-day trips that do occur are atypical in some way. For example, a vessel might make only one trip in a day if inclement weather or a mechanical issue prevented subsequent trips, both of which could affect fishing success (e.g., landings reported on the logbook report). Thus, results from matched-trip analyses for the southeast Florida region should be interpreted with caution given the relatively small sample sizes and the potential inclusion of atypical trips.

The utility of the analysis may have been limited to some extent by changes over time in protocols that determine the number of individuals of each species that should be measured in BP samples or in consistency in car- rying out those protocols. In general, the observed consistency and degree of correlation between CR-reported landings and number of fish sampled on the BP's suggests that the approach used was robust to this potential source of error with the exception of southeast Florida for certain species.

The analytical methods applied in this study to the SRHS data may prove useful for other fishery data, particularly in cases of self-reported data. The results of our analyses support the hypothesis that the SRHS dataset is a consistent, unbiased, and reliable source of information for assessing and managing stocks in the SEUS. Assessments using SRHS data in recent years have been focused on the more common species. In the future, when rare or data-limited species are assessed it will be imperative to understand the nature of these data before proceeding.

Because headboats make shortduration trips, relative to commercial vessels, and because they tend to target habitat rather than specific species, they collectively form a good design to sample the critical areas of the snapper-grouper complex. In addition, the vessels are spread out along the coast to cover the full geographic region of the SEUS. The temporal coverage of the catch-per-unit-effort (CPUE) information is the longest of any dataset in the southeast United States. These properties, particularly the targeting of habitat and not species, make this dataset quite useful for developing indices of abundance for a suite of species. We expect such indices to be less problematic than those generated from most other fishery-dependent CPUE time series in terms of reflecting relative abundance.

Recent improvements (e.g., in terms of data collection protocol, quality control and assurance, database management, electronic reporting, compliance, and inclusion of economic data) ensure that the SRHS will provide useful data for future stock assessments in the SEUS. These systematic changes provide scientists and managers with timely access to reliable data, resulting 
in improved fishery management advice for the snapper-grouper complex.

\section{Acknowledgments}

We thank the many headboat crew members and NMFS port agents for their efforts in providing data to this project throughout the many years, as well as Rusty Hudson for providing the historical image illustrating a headboat vessel in the SEUS.

\section{Literature Cited}

Burrell, V. G. 2000. The recreational fishery in South Carolina: the Little River story. Educ. Rep. 19, S.C. Dep. Nat. Resour., Mar. Resour. Div., Mar. Resour. Res. Inst., Charleston, S.C., 36 p.
Chester, A. J., G. R. Huntsman, P. A. Tester, and C. S. Manooch, III. 1984. South Atlantic Bight reef fish communities as represented in hook-and-line catches. Bull. Mar. Sci. 34:267-279.

Ellis, R. W., A. Rosen, and A. W. Moffett. 1958 A survey of the number of anglers and of their fishing effort and expenditures in the coastal recreational fishery of Florida. Fla. Board Conserv., Tech. Ser. 24, 49 p.

Grimes, C. B. 1978. Age, growth, and lengthweight relationship of vermilion snapper, Rhomboplites aurorubens, from North Carolina and South Carolina waters. Trans. Am. Fish. Soc. 107:454-456. (doi:https://doi. org/10.1577/1548-8659(1978) $107<454$ :AGA $\mathrm{LRO}>2.0 . \mathrm{CO} ; 2$.

Hammer, C., C. von Dorrien, C. C. E. Hopkins, F. W. Koster, E. M. Nilssen, M. St. John, and D. C. Wilson. 2010. Framework of stockrecovery strategies: analyses of factors affecting success and failure. ICES J. Mar. Sci. 67:1,849-1,855. (https://doi.org/10.1093/ icesjms/fsq122)
Huntsman, G. R. 1976. Offshore headboat fishing in North Carolina and South Carolina. Mar. Fish. Rev. 38(3):13-23.

Iglewicz, B., and D. C. Hoaglin. 1993. How to detect and handle outliers. ASQC, Milwaukee, Wisc., $87 \mathrm{p}$.

McCune, B., and J. B. Grace. 2002. Analysis of ecological communities. MjM Software Design, Gleneden Beach, Oreg., 304 p.

Power, E. A. 1959. Fishery statistics of the United States 1957. Bur. Commer. Fish., Stat. Dig. 44, 429 p.

Shertzer, K. W., and E. H. Williams. 2008. Fish assemblages and indicator species, reef fishes off the southeastern United States. Fish. Bull. 106:257-269.

and J. C. Taylor. 2009. Spatial structure and temporal patterns in a large marine ecosystem: exploited reef fishes of the southeast United States. Fish Res. 100:126-133. (https://doi.org/10.1016/j. fishres.2009.06.017). 
Appendix 1. - List of species present on Headboat Survey Trip Report for each form change from 1973 to 2005.

\begin{tabular}{|c|c|c|c|c|c|c|c|c|c|c|c|c|c|c|}
\hline & Form 1 & Form 2 & Form 3 & $\begin{array}{l}\text { Form } 4 \\
\text { (NC/SC) }\end{array}$ & $\begin{array}{l}\text { Form } 5 \\
\text { (GA/FL) }\end{array}$ & $\begin{array}{l}\text { Form } 6 \\
\text { (NC/SC) }\end{array}$ & $\begin{array}{l}\text { Form } 7 \\
\text { (GA/FL) }\end{array}$ & $\begin{array}{l}\text { Form } 8 \\
\text { (NC/SC) }\end{array}$ & $\begin{array}{l}\text { Form } 9 \\
\text { (GA/FL) }\end{array}$ & $\begin{array}{l}\text { Form } 10 \\
\text { (NC/SC) }\end{array}$ & $\begin{array}{l}\text { Form } 11 \\
\text { (GA/FL) }\end{array}$ & $\begin{array}{l}\text { Form } 12 \\
\text { (NC/SC) }\end{array}$ & $\begin{array}{l}\text { Form } 13 \\
\text { (GA/FL) }\end{array}$ & $\begin{array}{c}\text { Form } 14 \\
15,16\end{array}$ \\
\hline $\begin{array}{l}\text { Number of species } \\
\text { Years used ('YY-'YY) }\end{array}$ & $\begin{array}{c}24 \\
73-74\end{array}$ & $\begin{array}{c}26 \\
74-75\end{array}$ & $\begin{array}{c}30 \\
75-77\end{array}$ & $\begin{array}{c}35 \\
76-77\end{array}$ & $\begin{array}{c}32 \\
76-77\end{array}$ & $\begin{array}{c}35 \\
77-83\end{array}$ & $\begin{array}{c}31 \\
77-79\end{array}$ & $\begin{array}{c}36 \\
80-81\end{array}$ & $\begin{array}{c}67 \\
80-83\end{array}$ & $\begin{array}{c}62 \\
84-86\end{array}$ & $\begin{array}{c}71 \\
84-86\end{array}$ & $\begin{array}{c}65 \\
86-91\end{array}$ & $\begin{array}{c}74 \\
89-91\end{array}$ & $\begin{array}{c}69 \\
92-04\end{array}$ \\
\hline Strawberry grouper (Kitty Mitchell) & $\mathrm{x}$ & $\mathrm{x}$ & $\mathrm{x}$ & $\mathrm{x}$ & $\mathrm{x}$ & $\mathrm{x}$ & $\mathrm{x}$ & $\mathrm{x}$ & $\mathrm{x}$ & $\mathrm{x}$ & $\mathrm{x}$ & $\mathrm{x}$ & $\mathrm{x}$ & \\
\hline Warsaw grouper & $x$ & $\mathrm{x}$ & $x$ & $\mathrm{x}$ & $x$ & $\mathrm{x}$ & & $\mathrm{x}$ & & $\mathrm{x}$ & & $x$ & & $\mathrm{x}$ \\
\hline Red grouper & $\mathrm{x}$ & $\mathrm{x}$ & $\mathrm{x}$ & $\mathrm{x}$ & $\mathrm{x}$ & $\mathrm{x}$ & $\mathrm{x}$ & $\mathrm{x}$ & $\mathrm{x}$ & $\mathrm{x}$ & $\mathrm{x}$ & $\mathrm{x}$ & $\mathrm{x}$ & $\mathrm{x}$ \\
\hline Gag & $\mathrm{x}$ & $\mathrm{x}$ & $\mathrm{x}$ & $\mathrm{x}$ & $\mathrm{x}$ & $\mathrm{x}$ & $\mathrm{x}$ & $\mathrm{x}$ & $\mathrm{x}$ & $\mathrm{x}$ & $\mathrm{x}$ & $\mathrm{x}$ & $\mathrm{x}$ & $\mathrm{x}$ \\
\hline Scamp & $\mathrm{X}$ & $\mathrm{x}$ & $\mathrm{X}$ & $\mathrm{X}$ & $\mathrm{X}$ & $\mathrm{x}$ & $\mathrm{X}$ & $\mathrm{x}$ & $\mathrm{x}$ & $\mathrm{X}$ & $\mathrm{X}$ & $\mathrm{x}$ & $\mathrm{X}$ & $\mathrm{X}$ \\
\hline Black grouper & $\mathrm{x}$ & $\mathrm{x}$ & $\mathrm{x}$ & $\mathrm{x}$ & $\mathrm{x}$ & $\mathrm{x}$ & $\mathrm{x}$ & $\mathrm{x}$ & $\mathrm{x}$ & $\mathrm{x}$ & $\mathrm{x}$ & $\mathrm{x}$ & $\mathrm{x}$ & \\
\hline Yellowfin grouper & $\mathrm{x}$ & $\mathrm{x}$ & $\mathrm{x}$ & $\mathrm{x}$ & & $\mathrm{x}$ & & $\mathrm{x}$ & $\mathrm{x}$ & $\mathrm{X}$ & $\mathrm{x}$ & $\mathrm{x}$ & $\mathrm{X}$ & $\mathrm{x}$ \\
\hline Snowy grouper & $\mathrm{x}$ & $x$ & $x$ & $\mathrm{x}$ & & $x$ & & $x$ & & $x$ & & $\mathrm{x}$ & & $\mathrm{x}$ \\
\hline Other groupers & $x$ & $x$ & $x$ & $\mathrm{x}$ & & $x$ & & $\mathrm{x}$ & & $\mathrm{x}$ & & $\mathrm{x}$ & & \\
\hline Red snapper & $x$ & $x$ & $x$ & $x$ & $\mathrm{x}$ & $x$ & $\mathrm{x}$ & $x$ & $x$ & $x$ & $x$ & $x$ & $x$ & $x$ \\
\hline Yelloweye snapper & $\mathrm{X}$ & $\mathrm{X}$ & & $\mathrm{X}$ & & $\mathrm{X}$ & & $\mathrm{X}$ & & $\mathrm{X}$ & & $\mathrm{X}$ & & $\mathrm{X}$ \\
\hline Vermillion snapper & $x$ & $x$ & $x$ & $\mathrm{x}$ & $x$ & $x$ & $x$ & $\mathrm{x}$ & $x$ & $x$ & $x$ & $x$ & $x$ & $x$ \\
\hline Yellowtail snapper & $\mathrm{X}$ & & & & $\mathrm{X}$ & & $\mathrm{X}$ & & $\mathrm{X}$ & & $\mathrm{X}$ & & $\mathrm{X}$ & \\
\hline Other snapper & $\mathrm{x}$ & $x$ & $\mathrm{x}$ & $\mathrm{x}$ & & $x$ & & $x$ & & $x$ & & $x$ & & \\
\hline White grunt (Margate) & $\mathrm{x}$ & $x$ & $\mathrm{x}$ & $\mathrm{x}$ & & $x$ & & $\mathrm{x}$ & $\mathrm{x}$ & $\mathrm{X}$ & $\mathrm{x}$ & $\mathrm{x}$ & $\mathrm{x}$ & $\mathrm{x}$ \\
\hline Other grunts & $\mathrm{x}$ & $\mathrm{x}$ & $\mathrm{x}$ & $\mathrm{x}$ & $\mathrm{x}$ & $\mathrm{x}$ & $\mathrm{x}$ & $\mathrm{x}$ & $\mathrm{x}$ & $\mathrm{x}$ & $\mathrm{x}$ & $\mathrm{x}$ & $\mathrm{x}$ & \\
\hline Red porgy (silver snapper) & $x$ & $x$ & $x$ & $x$ & $x$ & $x$ & $x$ & $\mathrm{x}$ & $x$ & $x$ & $x$ & $x$ & $\mathrm{x}$ & $\mathrm{x}$ \\
\hline Other porgies & $\mathrm{x}$ & $\mathrm{x}$ & $\mathrm{x}$ & $\mathrm{x}$ & $\mathrm{x}$ & $x$ & $\mathrm{x}$ & $\mathrm{x}$ & $\mathrm{x}$ & $\mathrm{x}$ & $\mathrm{x}$ & $\mathrm{x}$ & $\mathrm{x}$ & \\
\hline Tilefish & $x$ & $\mathrm{x}$ & $\mathrm{x}$ & $\mathrm{x}$ & & $x$ & & $x$ & & $x$ & & $\mathrm{x}$ & & \\
\hline Amberjack & $\mathrm{x}$ & & $\mathrm{X}$ & $\mathrm{X}$ & $\mathrm{X}$ & $\mathrm{X}$ & $\mathrm{X}$ & $\mathrm{x}$ & $\mathrm{x}$ & $\mathrm{X}$ & $\mathrm{X}$ & $\mathrm{X}$ & $\mathrm{X}$ & $\mathrm{X}$ \\
\hline Triggerfish & $x$ & $x$ & $x$ & $x$ & $x$ & $x$ & $x$ & $x$ & $x$ & $x$ & $x$ & $x$ & $x$ & \\
\hline Dolphin & $x$ & & & & & & & & & $x$ & $x$ & $x$ & $x$ & $x$ \\
\hline Others & $\mathrm{x}$ & $\mathrm{x}$ & $\mathrm{x}$ & $x$ & & $\mathrm{x}$ & & $\mathrm{x}$ & & $\mathrm{x}$ & & $\mathrm{x}$ & & \\
\hline Boxes of Sea Bass & $\mathrm{x}$ & $\mathrm{x}$ & $\mathrm{x}$ & $\mathrm{x}$ & $\mathrm{x}$ & & & & & & & & & \\
\hline Rock hind & & $x$ & $\mathrm{x}$ & $\mathrm{x}$ & $x$ & $\mathrm{x}$ & $x$ & $\mathrm{x}$ & $x$ & $\mathrm{x}$ & $\mathrm{x}$ & $x$ & $x$ & $x$ \\
\hline Red hind & & $\mathrm{X}$ & $\mathrm{X}$ & $\mathrm{X}$ & $\mathrm{x}$ & $\mathrm{X}$ & $\mathrm{X}$ & $\mathrm{X}$ & $\mathrm{X}$ & $\mathrm{X}$ & $\mathrm{X}$ & $\mathrm{X}$ & $\mathrm{x}$ & $\mathrm{X}$ \\
\hline Tomtate & & $x$ & $\mathrm{x}$ & $\mathrm{x}$ & $x$ & $\mathrm{x}$ & $x$ & $x$ & $\mathrm{x}$ & $x$ & $x$ & $\mathrm{x}$ & $\mathrm{x}$ & $\mathrm{x}$ \\
\hline Knobbed porgy (Key West) & & $\mathrm{x}$ & $\mathrm{X}$ & $\mathrm{x}$ & $\mathrm{X}$ & $\mathrm{x}$ & $\mathrm{X}$ & $\mathrm{x}$ & $\mathrm{X}$ & $\mathrm{X}$ & $\mathrm{X}$ & $\mathrm{x}$ & $\mathrm{X}$ & $\mathrm{X}$ \\
\hline Other porgies (spot tail bream, scup, etc.) & & $\mathrm{x}$ & $\mathrm{x}$ & $\mathrm{x}$ & & $\mathrm{x}$ & & $\mathrm{x}$ & & $\mathrm{x}$ & & $\mathrm{x}$ & & \\
\hline Bream (spot-tail porgy) & & & $\mathrm{x}$ & $\mathrm{x}$ & $\mathrm{X}$ & $\mathrm{x}$ & $\mathrm{x}$ & $\mathrm{x}$ & $\mathrm{x}$ & $\mathrm{x}$ & $\mathrm{x}$ & $\mathrm{x}$ & $\mathrm{x}$ & $\mathrm{X}$ \\
\hline Scup (northern porgy) & & & $\mathrm{x}$ & $\mathrm{x}$ & & $\mathrm{x}$ & & $\mathrm{x}$ & & $\mathrm{x}$ & & $\mathrm{x}$ & & $\mathrm{x}$ \\
\hline Whitebone porgy (chocolate porgy) & & & $\mathrm{x}$ & $\mathrm{x}$ & $\mathrm{x}$ & $\mathrm{x}$ & $\mathrm{x}$ & $\mathrm{x}$ & $\mathrm{x}$ & $\mathrm{x}$ & $\mathrm{x}$ & $\mathrm{x}$ & $\mathrm{x}$ & $\mathrm{X}$ \\
\hline Squirrelfish & & & $x$ & $\mathrm{x}$ & $x$ & $x$ & $\mathrm{x}$ & $\mathrm{x}$ & $\mathrm{x}$ & $\mathrm{x}$ & $\mathrm{x}$ & $\mathrm{x}$ & $\mathrm{x}$ & $\mathrm{x}$ \\
\hline Yellowedge grouper & & & & $\mathrm{x}$ & & $\mathrm{x}$ & & $\mathrm{x}$ & & $\mathrm{x}$ & & $\mathrm{x}$ & & \\
\hline Other groupers (marbled, yellowfin) & & & & $\mathrm{x}$ & & $\mathrm{x}$ & & $\mathrm{X}$ & & $\mathrm{x}$ & & $\mathrm{x}$ & & \\
\hline Other snappers (mutton, etc.) & & & & $x$ & & $x$ & & $x$ & & $x$ & & $x$ & & \\
\hline Longspine porgy & & & & $x$ & $x$ & $x$ & $x$ & $x$ & $x$ & $x$ & $x$ & $x$ & $x$ & \\
\hline Nassau grouper & & & & & $\mathrm{X}$ & & $\mathrm{X}$ & & $\mathrm{X}$ & & $\mathrm{X}$ & & $\mathrm{X}$ & \\
\hline Other grouper (chocolate, etc.) & & & & & $\mathrm{x}$ & & $\mathrm{x}$ & & & & & & & \\
\hline Gray snapper & & & & & $\mathrm{x}$ & & $\mathrm{x}$ & & $\mathrm{x}$ & & $\mathrm{x}$ & & $\mathrm{x}$ & $\mathrm{x}$ \\
\hline Lane snapper & & & & & $\mathrm{X}$ & & $\mathrm{X}$ & & $\mathrm{X}$ & & $\mathrm{X}$ & & $\mathrm{x}$ & $\mathrm{X}$ \\
\hline Mutton snapper & & & & & $\mathrm{x}$ & & $\mathrm{x}$ & & $\mathrm{x}$ & & $\mathrm{x}$ & & $\mathrm{x}$ & $\mathrm{x}$ \\
\hline Other snappers (cubera, schoolmaster, silk) & & & & & $\mathrm{X}$ & & $\mathrm{X}$ & & & & & & & \\
\hline Porkfish & & & & & $\mathrm{x}$ & & $\mathrm{x}$ & & $\mathrm{x}$ & & $\mathrm{x}$ & & $\mathrm{x}$ & \\
\hline Amberina & & & & & $\mathrm{x}$ & & $\mathrm{x}$ & & $\mathrm{x}$ & & $\mathrm{x}$ & & $\mathrm{x}$ & \\
\hline Angelfish & & & & & $x$ & & $x$ & & $x$ & & $x$ & & $x$ & $x$ \\
\hline Pounds of Black Sea Bass & & & & & & $\mathrm{x}$ & $\mathrm{x}$ & $\mathrm{x}$ & $\mathrm{x}$ & $\mathrm{x}$ & $\mathrm{x}$ & $\mathrm{x}$ & $\mathrm{x}$ & \\
\hline Almaco jack & & & & & & & & $\mathrm{x}$ & $\mathrm{x}$ & $x$ & $\mathrm{x}$ & $\mathrm{x}$ & $\mathrm{x}$ & $\mathrm{x}$ \\
\hline Graysby & & & & & & & & & $\mathrm{x}$ & $\mathrm{x}$ & $\mathrm{x}$ & $\mathrm{x}$ & $\mathrm{x}$ & $\mathrm{x}$ \\
\hline Coney & & & & & & & & & $\mathrm{x}$ & $\mathrm{X}$ & $\mathrm{X}$ & $\mathrm{X}$ & $\mathrm{X}$ & \\
\hline Yellowmouth grouper & & & & & & & & & $\mathrm{x}$ & $\mathrm{x}$ & $\mathrm{x}$ & $x$ & $\mathrm{x}$ & $\mathrm{x}$ \\
\hline Yellowfin chocolate (yellowedge) & & & & & & & & & $\mathrm{x}$ & & $\mathrm{x}$ & & $\mathrm{x}$ & \\
\hline Jewfish & & & & & & & & & $x$ & & $x$ & & $x$ & \\
\hline Sailor's choice & & & & & & & & & $\mathrm{x}$ & & $\mathrm{x}$ & & $\mathrm{x}$ & \\
\hline Black margate & & & & & & & & & $x$ & & $x$ & & $x$ & \\
\hline French grunt & & & & & & & & & $\mathrm{x}$ & & $\mathrm{X}$ & & $\mathrm{x}$ & \\
\hline Bluestripe grunt & & & & & & & & & $\mathrm{x}$ & & $\mathrm{x}$ & & $\mathrm{x}$ & $\mathrm{x}$ \\
\hline Littlehead porgy & & & & & & & & & $\mathrm{X}$ & & $\mathrm{X}$ & $\mathrm{x}$ & $\mathrm{x}$ & $\mathrm{X}$ \\
\hline Saucereye porgy & & & & & & & & & $\mathrm{x}$ & & $\mathrm{x}$ & & $\mathrm{x}$ & \\
\hline Sheepshead porgy & & & & & & & & & $\mathrm{x}$ & $\mathrm{x}$ & $\mathrm{x}$ & $\mathrm{x}$ & $\mathrm{x}$ & \\
\hline Jolthead porgy & & & & & & & & & $\mathrm{x}$ & & $\mathrm{x}$ & & $\mathrm{x}$ & $\mathrm{x}$ \\
\hline Blackfin snapper & & & & & & & & & $\mathrm{x}$ & $\mathrm{X}$ & $\mathrm{x}$ & $\mathrm{x}$ & $\mathrm{x}$ & $\mathrm{x}$ \\
\hline Cubera snapper & & & & & & & & & $\mathrm{x}$ & & $\mathrm{x}$ & & $\mathrm{x}$ & $\mathrm{x}$ \\
\hline Schoolmaster snapper & & & & & & & & & $\mathrm{x}$ & & $\mathrm{x}$ & & $\mathrm{x}$ & \\
\hline Silk snapper & & & & & & & & & $\mathrm{X}$ & & $\mathrm{X}$ & & $\mathrm{X}$ & $\mathrm{X}$ \\
\hline Black snapper & & & & & & & & & $x$ & & $x$ & & $x$ & \\
\hline Queen triggerfish & & & & & & & & & $x$ & $x$ & $x$ & $x$ & $x$ & $x$ \\
\hline Gray triggerfish & & & & & & & & & $\mathrm{x}$ & $\mathrm{x}$ & $\mathrm{x}$ & $\mathrm{x}$ & $\mathrm{x}$ & $\mathrm{X}$ \\
\hline Ocean triggerfish & & & & & & & & & $\mathrm{x}$ & & $\mathrm{x}$ & & $\mathrm{x}$ & \\
\hline Gray tilefish (blueline) & & & & & & & & & $\mathrm{x}$ & $\mathrm{x}$ & $\mathrm{x}$ & $\mathrm{x}$ & $\mathrm{x}$ & $\mathrm{x}$ \\
\hline Sand tilefish (sandeel) & & & & & & & & & $\mathrm{X}$ & $\mathrm{X}$ & $\mathrm{X}$ & $\mathrm{X}$ & $\mathrm{X}$ & $\mathrm{X}$ \\
\hline African pompano & & & & & & & & & $x$ & $x$ & $x$ & $\mathrm{x}$ & $\mathrm{x}$ & $x$ \\
\hline Blue runner & & & & & & & & & $\mathrm{x}$ & $\mathrm{X}$ & $\mathrm{x}$ & $\mathrm{x}$ & $\mathrm{x}$ & $\mathrm{x}$ \\
\hline
\end{tabular}


Appendix 1.-Continued

\begin{tabular}{|c|c|c|c|c|c|c|c|c|c|c|c|c|c|c|}
\hline & Form 1 & Form 2 & Form 3 & $\begin{array}{l}\text { Form } 4 \\
\text { (NC/SC) }\end{array}$ & $\begin{array}{l}\text { Form } 5 \\
\text { (GA/FL) }\end{array}$ & $\begin{array}{l}\text { Form } 6 \\
\text { (NC/SC) }\end{array}$ & $\begin{array}{l}\text { Form } 7 \\
(\mathrm{GA} / \mathrm{FL})\end{array}$ & $\begin{array}{l}\text { Form } 8 \\
\text { (NC/SC) }\end{array}$ & $\begin{array}{l}\text { Form } 9 \\
(\mathrm{GA} / \mathrm{FL})\end{array}$ & $\begin{array}{l}\text { Form } 10 \\
\text { (NC/SC) }\end{array}$ & $\begin{array}{l}\text { Form } 11 \\
(\mathrm{GA} / \mathrm{FL})\end{array}$ & $\begin{array}{l}\text { Form } 12 \\
\text { (NC/SC) }\end{array}$ & $\begin{array}{l}\text { Form } 13 \\
\text { (GA/FL) }\end{array}$ & $\begin{array}{c}\text { Form } 14 \\
15,16\end{array}$ \\
\hline $\begin{array}{l}\text { Number of species } \\
\text { Years used ('YY-'YY) }\end{array}$ & $\begin{array}{c}24 \\
73-74\end{array}$ & $\begin{array}{c}26 \\
74-75\end{array}$ & $\begin{array}{c}30 \\
75-77\end{array}$ & $\begin{array}{c}35 \\
76-77\end{array}$ & $\begin{array}{c}32 \\
76-77\end{array}$ & $\begin{array}{c}35 \\
77-83\end{array}$ & $\begin{array}{c}31 \\
77-79\end{array}$ & $\begin{array}{c}36 \\
80-81\end{array}$ & $\begin{array}{c}67 \\
80-83\end{array}$ & $\begin{array}{c}62 \\
84-86\end{array}$ & $\begin{array}{c}71 \\
84-86\end{array}$ & $\begin{array}{c}65 \\
86-91\end{array}$ & $\begin{array}{c}74 \\
89-91\end{array}$ & $\begin{array}{c}69 \\
92-04\end{array}$ \\
\hline Rainbow runner & & & & & & & & & $\mathrm{x}$ & & $x$ & & $\mathrm{x}$ & $\mathrm{x}$ \\
\hline King mackerel & & & & & & & & & $\mathrm{x}$ & $\mathrm{x}$ & $x$ & $\mathrm{x}$ & $\mathrm{x}$ & $\mathrm{x}$ \\
\hline Spanish mackerel & & & & & & & & & $\mathrm{x}$ & $\mathrm{X}$ & $\mathrm{x}$ & $\mathrm{x}$ & $\mathrm{X}$ & $\mathrm{X}$ \\
\hline Cero & & & & & & & & & $\mathrm{X}$ & $\mathrm{X}$ & $\mathrm{X}$ & $\mathrm{x}$ & $\mathrm{X}$ & \\
\hline Bluefish & & & & & & & & & $x$ & $x$ & $x$ & $x$ & $x$ & $x$ \\
\hline Bigeye (toro) & & & & & & & & & $\mathrm{x}$ & $\mathrm{x}$ & $\mathrm{x}$ & $\mathrm{x}$ & $\mathrm{x}$ & $\mathrm{x}$ \\
\hline Bonito & & & & & & & & & $\mathrm{X}$ & $\mathrm{x}$ & $\mathrm{X}$ & $\mathrm{X}$ & $\mathrm{X}$ & $\mathrm{X}$ \\
\hline Barracuda & & & & & & & & & $x$ & $x$ & $x$ & $x$ & $x$ & $x$ \\
\hline Cobia & & & & & & & & & $\mathrm{x}$ & $\mathrm{x}$ & $\mathrm{x}$ & $\mathrm{x}$ & $\mathrm{x}$ & $\mathrm{x}$ \\
\hline Marbled grouper & & & & & & & & & & $x$ & & $x$ & & \\
\hline Dog snapper & & & & & & & & & & & $\mathrm{X}$ & & $\mathrm{X}$ & \\
\hline Hogfish (hog snapper) & & & & & & & & & & $x$ & $x$ & $\mathrm{x}$ & $\mathrm{x}$ & $\mathrm{x}$ \\
\hline Pigfish & & & & & & & & & & $\mathrm{X}$ & & $\mathrm{x}$ & & \\
\hline Spadefish & & & & & & & & & & $x$ & $\mathrm{x}$ & $\mathrm{x}$ & $\mathrm{x}$ & $x$ \\
\hline Sand perch & & & & & & & & & & $x$ & & $x$ & $x$ & $x$ \\
\hline Wahoo & & & & & & & & & & $\mathrm{x}$ & & $\mathrm{x}$ & & \\
\hline Bank sea bass & & & & & & & & & & & & $\mathrm{X}$ & $\mathrm{x}$ & $\mathrm{X}$ \\
\hline Spottail pinfish & & & & & & & & & & & & $\mathrm{x}$ & $\mathrm{x}$ & $\mathrm{x}$ \\
\hline Black sea bass (\# and weight) & & & & & & & & & & & & & & $\mathrm{x}$ \\
\hline Pinfish & & & & & & & & & & & & & & $\mathrm{x}$ \\
\hline Sharpnose shark & & & & & & & & & & & & & & $\mathrm{x}$ \\
\hline Sandbar shark & & & & & & & & & & & & & & $\mathrm{x}$ \\
\hline Blacktip shark & & & & & & & & & & & & & & $x$ \\
\hline Smooth dogfish & & & & & & & & & & & & & & $\mathrm{x}$ \\
\hline Nurse shark & & & & & & & & & & & & & & $\mathrm{x}$ \\
\hline Dusky shark & & & & & & & & & & & & & & $\mathrm{x}$ \\
\hline Remora & & & & & & & & & & & & & & $\mathrm{x}$ \\
\hline Banded rudderfish & & & & & & & & & & & & & & $\mathrm{x}$ \\
\hline Yellowfin tuna & & & & & & & & & & & & & & $\mathrm{X}$ \\
\hline Short bigeye & & & & & & & & & & & & & & $\mathrm{x}$ \\
\hline Spotted soapfish & & & & & & & & & & & & & & $\mathrm{x}$ \\
\hline Tattler & & & & & & & & & & & & & & $\mathrm{x}$ \\
\hline Inshore lizardfish & & & & & & & & & & & & & & $\mathrm{X}$ \\
\hline
\end{tabular}


Appendix 2.- Southeast Region Headboat Survey eLog web based portal.

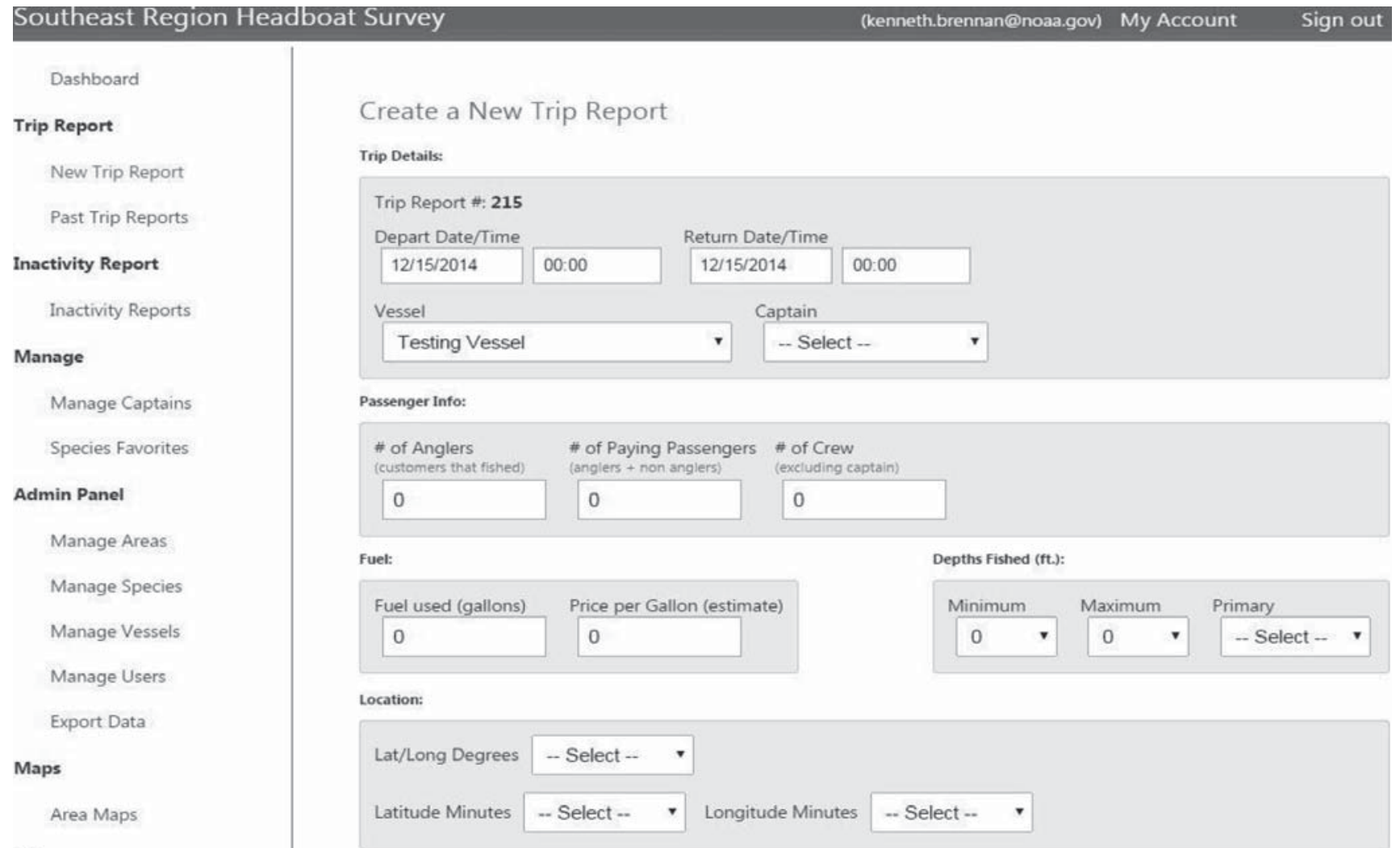

\section{SAVE TRIP REPORT INFORMATION}

